\title{
Evaluation of the impact behaviour of AlSi10Mg alloy produced using laser additive manufacturing
}

Luca Girelli a, Maverick Giovagnoli ${ }^{\mathrm{b}}$, Marialaura Tocci a, Annalisa Pola ${ }^{\mathrm{a}}$, Annalisa Fortini ${ }^{\mathrm{b}}$, Mattia Merlin ${ }^{\mathrm{b}}$, Giovina Marina La Vecchia ${ }^{\mathrm{a}}$

${ }^{a}$ University of Brescia, Department of Mechanical and Industrial Engineering, via Branze 38, 25123 Brescia, Italy

${ }^{b}$ University of Ferrara, Department of Engineering, via Saragat 1, 44122 Ferrara, Italy

Corresponding author: Annalisa Pola, annalisa.pola@unibs.it, via Branze 38, 25123, Brescia, Italy

\begin{abstract}
In the present study, instrumented impact strength tests were carried out on Charpy AlSi10Mg samples produced using laser additive manufacturing in order to accurately investigate the influence of building directions, heat treatment parameters and also the effect of Hot Isostatic Pressing (HIP) on their impact properties. AlSi10Mg cast samples were also tested for comparison. In addition to metallographic inspections, a deep characterization of the fracture surfaces in all the analysed conditions was performed. Microstructural features were also correlated to the impact properties: absorbed energy, peak force, crack nucleation and propagation energies. It was found that additive manufactured samples in as-produced condition exhibit the best performance due to their peculiar microstructure. HIP, followed by T6 heat treatment, is positive for the alloy properties since it effectively reduces porosities, which are a favourable path for crack propagation. Building direction has a clear effect on the fracture propagation. Samples in as-produced condition display greater unevenness of the fracture surface in the horizontal direction than in the vertical direction. This trend is less evident after heat treatment, but still detectable. The fractal dimension of the fracture surfaces is a quantitative parameter sensitive to the building orientation of samples and to the performed heat treatments.
\end{abstract}

Keywords: Impact strength; Additive manufacturing; AlSi10Mg; Optical microscopy; Electron microscopy; Fracture behaviour 


\section{Introduction}

Nowadays, one of the most innovative manufacturing processes for metallic materials is Additive Manufacturing (AM) technology. It consists in the layer-by-layer build-up of the component [1] and it offers various advantages as compared with conventional metal manufacturing processes, such as unrivalled design freedom, near-zero material waste and the reduction of expensive tooling, together with improved mechanical properties [1-3]. Today, this technology is used for medical applications, such as dental prostheses, bone scaffolds or orthopaedic implants [4], due to the possibility of producing parts characterized by complex architecture, small size and made of high melting temperature alloys [4-6]. Other applications are related to the aircraft, automotive and mechanical industries, as such as lightweight scaffold structures for aeronautical applications $[5,7]$, gas turbine blades and turbocharger rotors [7], heat exchangers [7], etc.

Nevertheless, metal AM still suffers from certain limitations, as such as the restricted size of the components due to the machine chamber size [8], the process speed, the surface finish and accuracy, the product anisotropy, the need for a completely new design process, the lack of international standards and practices, and also the costs of machines and powders [9].

Given that it is a new and emerging technology, the design of the alloys, the optimization of process parameters and the characterization of the products obtained are key topics of research in scientific and industrial fields [10]. Various metals are used for AM, in particular stainless steel [11, 12], titanium [13, 14], nickel $[15,16]$ and aluminium alloys [17-19]. With regards to aluminium alloys, lately various compositions have been tested in order to better understand the role of Si content [20] or to improve the material performance by adding strengthening elements [21] or nanoparticles [22]. Nevertheless, the most widely used material is the AlSi10Mg alloy, i.e. a traditional casting alloy composition, which has proved particularly suitable for Additive Manufacturing processes [2] and ensures good mechanical properties, low thermal expansion and significant corrosion resistance of the final parts [23].

The microstructural and mechanical properties of components produced by this technology are characterized in abundance in scientific literature [24-27]. For AlSi10Mg components obtained by laser additive manufacturing in particular, one peculiar feature highlighted by these investigations is the ultrafine microstructure characterized by the cellular $\alpha$-Al phase and fibrous Si particles [18]. This microstructure is obtained through the very high cooling rates typical of this manufacturing process and it is responsible for the remarkable hardness and tensile strength of AM parts [28, 29]. In fact, an extremely fine microstructure plays a key role in hindering dislocation motion and, therefore, enhancing material performance $[28,30]$. 
Several studies have also considered the influence of processing parameters [29, 31, 32] and testing procedures [33] on the tensile properties of AM AlSi10Mg parts. In general, their performance is superior in comparison with the corresponding conventionally manufactured components.

The microstructural quality is fundamental also for other material properties, such as fatigue [25, 34, 35], wear resistance [36] or creep behaviour [29].

The influence of $\mathrm{T} 6$ heat treatment on mechanical properties is another important aspect to consider, since it is reported to strongly affect the AM material microstructure and, therefore, final performance $[24,37]$.

Despite the abundant studies on the mechanical characterization of additive manufactured Al-Si parts, according to the authors' knowledge, the impact behaviour of Al-Si components produced by AM technology has rarely been investigated [26], as well as for other alloys [38-40], although the evaluation of the impact behaviour is fundamental to several applications where rapid loading conditions are present. Regarding Al-Si alloys, for instance, Kempen et al. [26] found that AM AlSi10Mg samples showed a slightly higher Charpy impact energy than cast AlSi10Mg specimens, while no strong influence of the building direction was identified. However, an interpretation of the fracture mechanism based on the analysis of the fractured surface is not available in scientific literature. For this reason, in this study, Charpy impact behaviour of AM AlSi10Mg samples produced by laser additive manufacturing was accurately investigated. The effect of T6 (solution, quenching and ageing) heat treatment and Hot Isostatic Pressing (HIP) was also evaluated in order to better characterize the material performance and its possible enhancement. The observation of fracture surfaces allowed the study of the influence of the microstructure on material behaviour, with particular attention to the effect of the building direction. The same investigation was carried out on cast AlSi10Mg samples produced by conventional gravity casting, in order to evaluate the different microstructures and fracture mechanisms.

\section{Experimental procedure}

The AM specimens were produced in both horizontal $(\mathrm{H})$ and vertical (V) directions (Figure 1) using Direct Metal Laser Sintering powder bed technology, with an EOS M290 system (400 W, Yb laser fibre; F-theta lens; $30 \mathrm{~A}$ and $400 \mathrm{~V}$ power supply; $7000 \mathrm{hPa}, 20 \mathrm{~m}^{3} / \mathrm{h}$ inert gas supply; $100 \mu \mathrm{m}$ focus diameter; EOS GmbH Electro Optical System [41]). Commercial EOS Aluminium AlSi10Mg powder was used and the process took place in argon atmosphere. The samples had a square cross section of $12 \mathrm{~mm} \times 12 \mathrm{~mm}$ and a length of $57 \mathrm{~mm}$. 


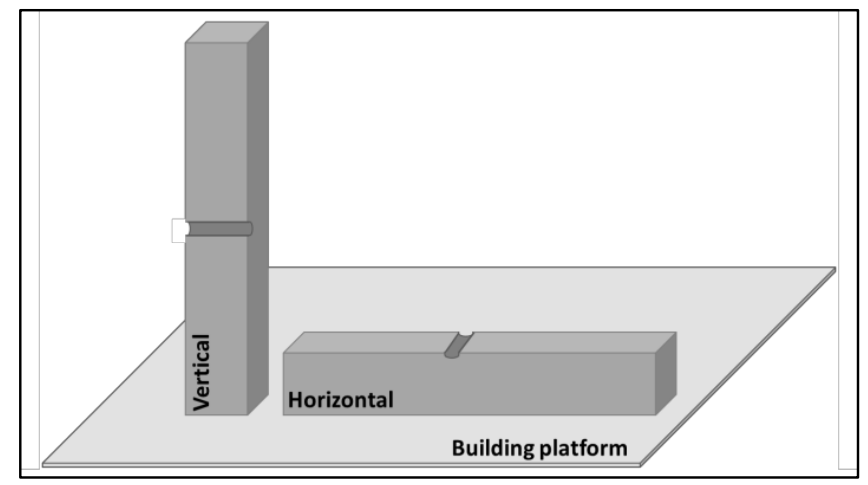

Fig. 1. Diagram of the orientation of AM samples on the building platform in the additive manufacturing system.

Specimens of size $12 \mathrm{~mm}$ x $12 \mathrm{~mm}$ x $57 \mathrm{~mm}$ were machined from an industrial component produced in AlSi10Mg alloy by conventional gravity casting (GC). Care was given to taking the specimens from areas of the casting characterized by the same thickness (approximately $20 \mathrm{~mm}$ ) in order to ensure the same solidification and cooling conditions and, thus, the same microstructure. The chemical composition of both AM [42] and GC [43] alloy, measured by an optical emission spectrometer, is shown in Table 1.

\begin{tabular}{ccccccccc}
\hline & Si & Mg & Fe & Mn & Cu & Na & Sr & Al \\
\hline AM & $10.24 \pm 0.09$ & $0.396 \pm 0.001$ & $0.213 \pm 0.002$ & $<0.002$ & $<0.002$ & $<0.002$ & $<0.001$ & balance \\
GC & $9.89 \pm 0.30$ & $0.376 \pm 0.037$ & $0.508 \pm 0.021$ & $0.403 \pm 0.019$ & $0.207 \pm 0.011$ & $0.007 \pm 0.002$ & $<0.001$ & balance
\end{tabular}

Table 1. Chemical composition (wt. \%) of AlSi10Mg alloy produced by additive manufacturing $(A M)$ and gravity casting $(G C)$.

The AM and GC specimens were tested in both as-produced and T6 heat-treated conditions. T6 parameters with long solution time were chosen based on a previous study for AM parts [36]. In addition, a shorter solution time, known to guarantee a lower enlargement of gas porosity in AM products [37], was also considered in order to evaluate its effect on impact properties. Moreover, the effect of HIP, before long time solution treatment, was taken into account for AM parts in order to reduce the porosity. In this paper, the general term porosity is used to identify both gas and lackof-fusion porosities, as they are the main types of porosity found in metal AM components [44]. In more detail, different types of porosity can be observed in AM aluminium parts. Depending on the source, in fact, porosities can be classified in powder-induced, process-induced or artefacts of solidification [45]. The first type consists in spherical defects related to the intrinsic porosity of the powder and to hydrogen absorption due to moisture. Process induced porosity includes both 
spherical and non-spherical defects of different sizes, attributable to the process parameters. In particular, the almost spherical ones are related to entrapment of the inert gas present in the building environment during laser scanning and the subsequent fast solidification, but also to melt splashing, Marangoni flow or gas entrapment due to vaporization of low melting point constituents in the alloy $[17,19,46-49]$. The non-spherical process-induced defects are the so-called lack of fusion porosities, caused by a poor overlap of melting pools during the building process resulting in incomplete melting of the powder. Finally, shrinkage porosity caused by solidification can also be found. Where a specific type is referred to in the text, a precise description is added.

The list of the different treatment conditions is presented in Table 2. During solution and ageing treatment, the temperature was monitored by a Delta Hom HD 2128.1 thermocouple. Quenching was performed in water at $65^{\circ} \mathrm{C}$.

\begin{tabular}{|c|c|c|c|c|c|}
\hline Process & Designation & Hot Isostatic Pressing & Solution & Quenching & Ageing \\
\hline $\mathbf{A M}$ & as-produced & - & - & - & - \\
\hline $\mathbf{A M}$ & $540^{\circ} \mathrm{C} 1 \mathrm{~h}-180^{\circ} \mathrm{C} 2 \mathrm{~h}$ & - & $540{ }^{\circ} \mathrm{C} 1 \mathrm{~h}$ & $65^{\circ} \mathrm{C}$ & $180^{\circ} \mathrm{C} 2 \mathrm{~h}$ \\
\hline $\mathbf{A M}$ & $540^{\circ} \mathrm{C} 9 \mathrm{~h}-160^{\circ} \mathrm{C} 4 \mathrm{~h}$ & - & $540^{\circ} \mathrm{C} 9 \mathrm{~h}$ & $65^{\circ} \mathrm{C}$ & $160^{\circ} \mathrm{C} 4 \mathrm{~h}$ \\
\hline $\mathbf{A M}$ & $H I P-540^{\circ} \mathrm{C} 9 \mathrm{~h}-160^{\circ} \mathrm{C} 4 \mathrm{~h}$ & $520^{\circ} \mathrm{C} 2 \mathrm{~h} 100$ bar & $540{ }^{\circ} \mathrm{C} 9 \mathrm{~h}$ & $65^{\circ} \mathrm{C}$ & $160^{\circ} \mathrm{C} 4 \mathrm{~h}$ \\
\hline GC & as-produced & - & - & - & - \\
\hline GC & $540^{\circ} \mathrm{C} 1 \mathrm{~h}-180^{\circ} \mathrm{C} 2 \mathrm{~h}$ & - & $540^{\circ} \mathrm{C} 1 \mathrm{~h}$ & $65^{\circ} \mathrm{C}$ & $180^{\circ} \mathrm{C} 2 \mathrm{~h}$ \\
\hline GC & $540^{\circ} \mathrm{C} 9 \mathrm{~h}-160^{\circ} \mathrm{C} 4 \mathrm{~h}$ & - & $540^{\circ} \mathrm{C} 9 \mathrm{~h}$ & $65^{\circ} \mathrm{C}$ & $160^{\circ} \mathrm{C} 4 \mathrm{~h}$ \\
\hline
\end{tabular}

Table 2. Tested conditions of both AM and GC samples.

After heat treatment, all the surfaces of the specimens were machined to the standard size of Unotched Charpy samples (10 $\mathrm{mm} \times 10 \mathrm{~mm} \times 55 \mathrm{~mm})$ in accordance with ASTM E23 standard [50]. In Figure 1, the position of the U-notch is also shown for both horizontal and vertical samples.

The porosity level before and after heat treatment was investigated by density measurements to correlate it to the impact toughness of the material. The density was measured using the hydrostatic weighing method [51] on 3 different samples for each investigated condition. According to this method, the samples were weighed in air and, subsequently, in distilled water. A suitable weight scale (Gibertini E42-B) was used [37].

Charpy impact tests were performed at room temperature on 4 samples for each investigated condition. A CEAST instrumented pendulum with an available energy of $50 \mathrm{~J}$ was used and the force-displacement curves were calculated according to the ISO 14556:2015 standard. Charpy 
instrumented test requires that the samples, placed on the supports, are broken with a force that is measured by a load cell positioned directly on the hammer while the displacement is evaluated through an encoder. During impact, data were recorded by the CEAST DAS 64K and analysed by the Visual IMPACT software, which enabled the total absorbed energy of the impact to be computed as the area under the force-displacement curve. Figure 2 shows a summary of the described facilities together with an example of force-displacement curve.

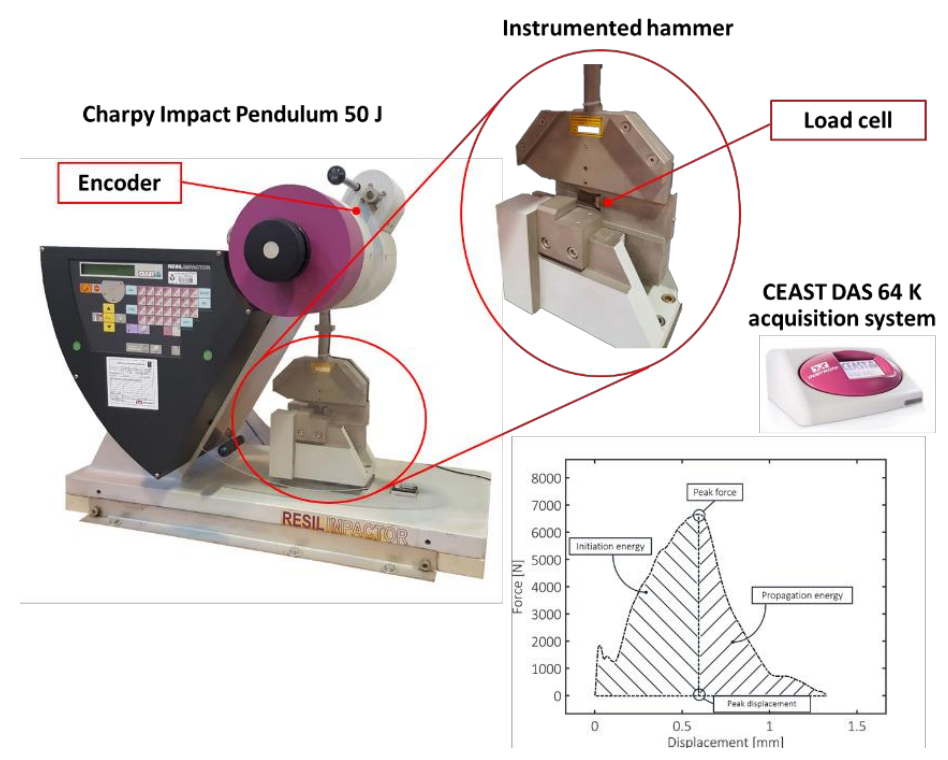

Fig. 2. Instrumented Charpy impact pendulum used for the impact tests.

The total energies absorbed by the specimens in the different conditions were correlated with the microstructural features. Raw data acquired during the impact tests were analysed by means of a tailored Matlab ${ }^{\circledR}$ code. Four significant parameters were calculated from the force-displacement curve of the instrumented impact tests:

- peak force, corresponding to the maximum force value recorded during the test;

- peak displacement, which corresponds to the displacement relative to the peak force;

- initiation energy, which is the amount of energy absorbed by the specimen at peak force (calculated as the area under the force-displacement curve up to peak force);

- propagation energy, which is the amount of energy absorbed by the specimen from peak force to the end of the test.

After Charpy tests, characterizations were performed using a Leica DMI 5000 M optical microscope to analyse the most important microstructural features and the fracture profiles. Microstructural investigations were carried out on metallographic sections cut out perpendicularly to the fracture surface, as reported in Figure 3. The specimens were polished up to mirror finishing. As-produced AM microstructure was observed after Keller etching ( $1 \% \mathrm{HF}, 1.5 \% \mathrm{HCl}, 2.5 \%$ 
$\mathrm{HNO}_{3}$ and $95 \% \mathrm{H}_{2} \mathrm{O}$ ) for $30 \mathrm{~s}$, according to the ASTM E407 standard [52]. The fracture surfaces were also investigated by a Zeiss EVO MA 15 scanning electron microscope.

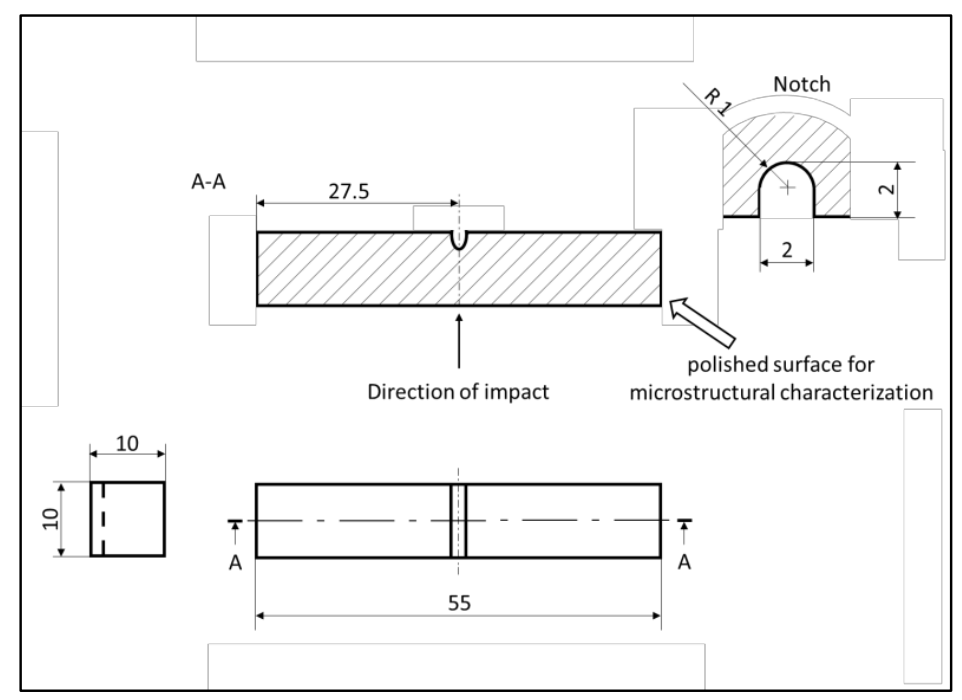

Fig. 3. Diagram of sample geometry with indication of the surface observed for microstructural characterization.

Moreover, in AM specimens, the fractal dimension $D_{f}$ of fracture surfaces was quantitatively evaluated by a Talysurf CCI-Lite non-contact 3D profilometer (Taylor-Hobson). In order to calculate this parameter, each fracture surface was first cleaned in an ultrasonic bath to remove any contaminations, and then an area of $12 \mathrm{~mm}^{2}(6 \mathrm{~mm} \times 2 \mathrm{~mm}$ in the directions perpendicular and parallel to the notch, respectively) was investigated. The spatial coordinates of the surface points were acquired with a resolution of $0.84 \mu \mathrm{m}$ in $\mathrm{x}-\mathrm{y}$ scanning direction. Each fracture profile along the direction perpendicular to the notch, i.e. in the direction of crack propagation, was reconstructed and analysed by means of a tailored Matlab ${ }^{\circledR}$ code. Fractal dimension $\mathrm{D}_{\mathrm{f}}$, which is a descriptor of the topographic features of the fracture surfaces, was evaluated by the Box-Counting method. Basically, the space occupied by the profile was filled with boxes of arbitrary size $\delta$ (ranging from 1 $\mu \mathrm{m}$ to $1000 \mu \mathrm{m}$ ) and the number $\mathrm{N}$ of boxes necessary to recover the entire profile was evaluated. Plotting $\delta$-N data in a log-log plot [53-56], the fractal dimension was calculated starting from the slope of the linear part of the curve. 


\section{Results and discussion}

\section{Microstructure and density}

The typical AM pools, composed of semi-circular sections in the building direction, can be observed after Keller etching (Figure 4a-b). Small porosities were also detected along the specimens, in accordance with the analysis performed by many authors on AM products [17, 19, 46-48]. In particular, detailed analysis of the microstructures highlighted the fact that porosities are mainly located inside the melt pools, although sometimes they appear along the interface between adjacent scan tracks or at the boundary between consecutive layers. This is in accordance with the literature [48, 57]. In fact, as reported by Weingarten et al. [57], gas porosities that nucleate at the melting front, i.e. at the interface between the melting pool and the already solidified underlying substrate, can easily escape from the melt pool surface. On the other hand, pores due to gas entrapment that nucleate near the solidification front, do not have enough time to escape prior being entrapped by the solidification front itself. Thus, they will remain in the inner part of the melt pool or at its sides, i.e. at the track-track interfaces. Only rarely do they appear at the inter-layer interfaces.

After T6 treatment (Figures $4 \boldsymbol{c}-f$ ) a coarsening of Si particles can be detected. Moreover, the melt pool boundaries that characterize the as-produced AM samples (Figures $\mathbf{4} \boldsymbol{a}-\boldsymbol{b}$ ) cannot be identified at the considered magnification, due to an almost complete loss of the cellular microstructure after heat treatment. In addition, a considerable increase of gas porosity is observed.

The HIP treatment, performed before the solution treatment, considerably affects the microstructure (Figure $4 \boldsymbol{g}-\boldsymbol{h}$ ) leading to a significant porosity reduction. 


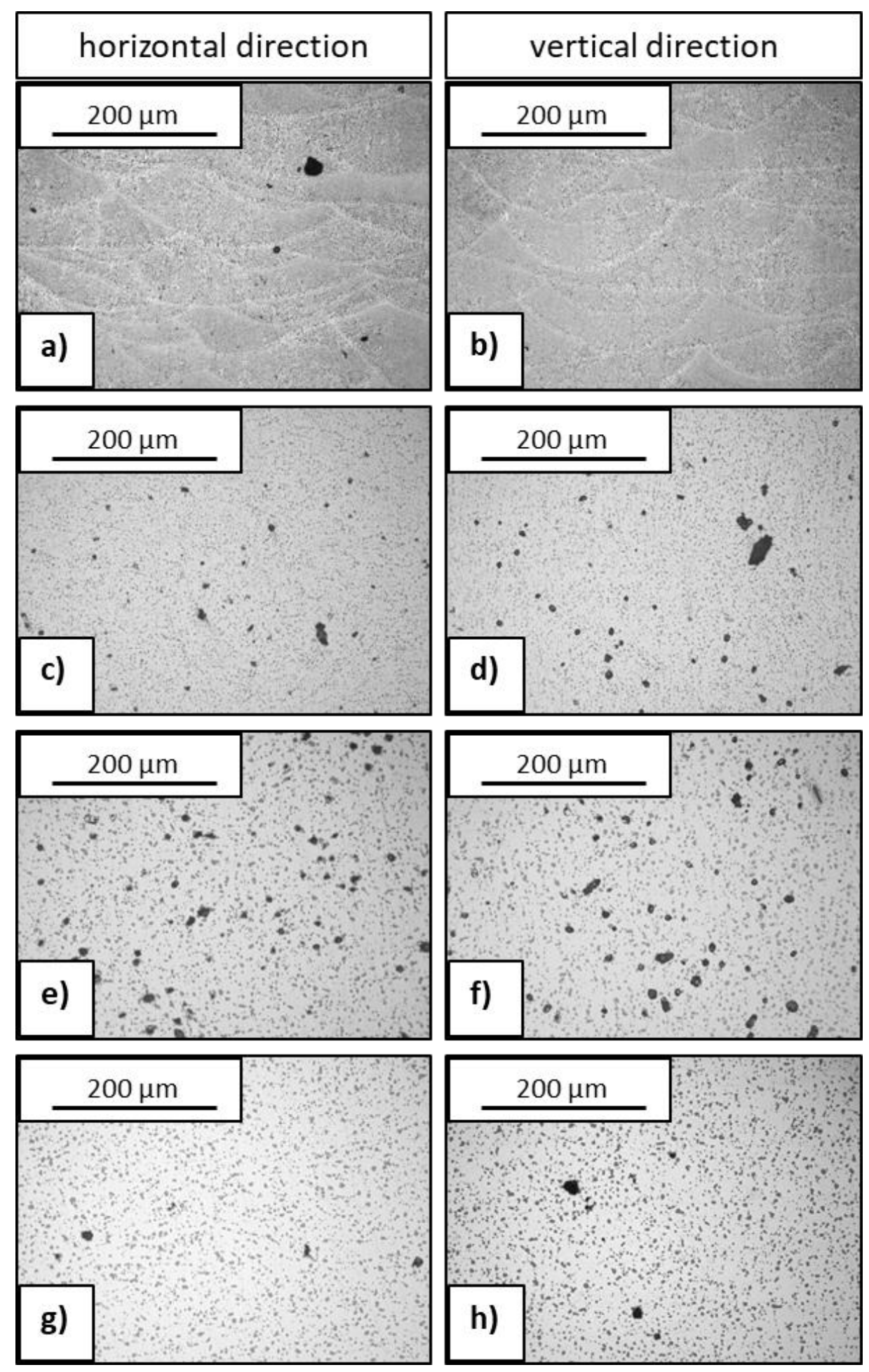

Fig. 4. Micrographs of AM samples in (a, b) as-produced, (c, d) $540^{\circ} \mathrm{C} 1 \mathrm{~h}-180^{\circ} \mathrm{C} 2 \mathrm{~h},(e, f) 540^{\circ} \mathrm{C}$ $9 h-160^{\circ} \mathrm{C} 4 \mathrm{~h}$ and $(\mathrm{g}, \mathrm{h}) \mathrm{hip}-540^{\circ} \mathrm{C} 9 \mathrm{~h}-160^{\circ} \mathrm{C} 4 \mathrm{~h}$ conditions, in $(a, c, e, g)$ horizontal and $(b, d, f$, h) vertical orientations.

The typical microstructure at high magnification of an as-produced AM sample (according to Figure 3) built both in horizontal and vertical directions is depicted in Figure 5. The SEM 
micrographs show a microstructure characterized by very fine $\alpha$-Al cellular grains and by superfine Si particles at the edges $[1,27,58]$.
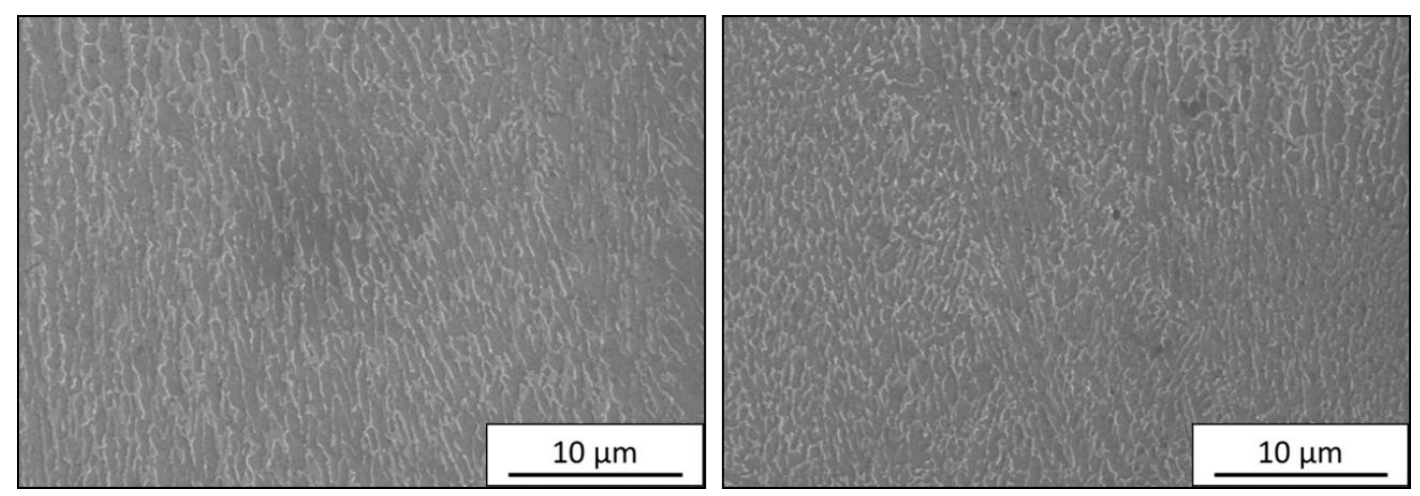

Fig. 5. SEM microstructure of as-produced AM sample in (a) horizontal and (b) vertical orientations.

Concerning the cast samples, as-produced GC microstructure (Figure $6 \boldsymbol{a}$ ) is characterized by the typical $\alpha$-Al dendritic phase (light grey) surrounded by the eutectic structure. Fine eutectic $\mathrm{Si}$ lamellae are clearly visible. In addition, some coarse Fe-rich intermetallics were detected, while porosities were seldom found. The spheroidization of the eutectic Si particles during solution treatments is visible in Figures $\boldsymbol{6} \boldsymbol{b}$-c , even though some small Si lamellae are still present. 

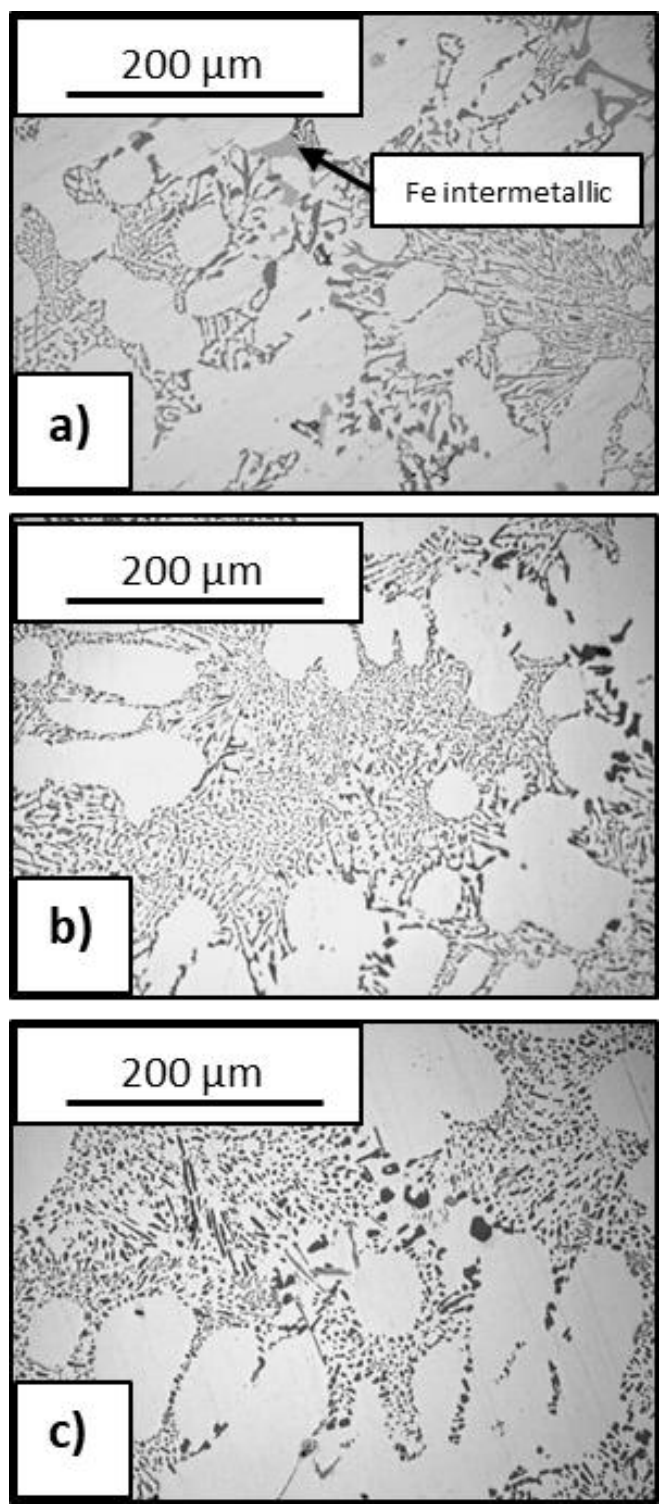

Fig. 6. Micrographs of GC samples in (a) as-produced, (b) $540^{\circ} \mathrm{C} 1 \mathrm{~h}-180^{\circ} \mathrm{C} 2 \mathrm{~h}$ and (c) $540^{\circ} \mathrm{C} 9 \mathrm{~h}$ $160^{\circ} \mathrm{C} 4 \mathrm{~h}$.

The results of density measurements are summarized in Table 3. The AM sample shows a very high density $\left(2.68 \mathrm{~g} / \mathrm{cm}^{3}\right)$ in as-produced condition, while it decreases after heat treatments. This significant reduction is related to the exposure to high temperatures during solution treatment and it increases with increasing treatment duration, as already visible from microstructure analysis (Figures $4 \boldsymbol{e}-\boldsymbol{f}$ ) and demonstrated in a previous study by the authors [59]. HIP acts positively towards reducing porosity. However, the density values of the as-produced material cannot be reached.

On the contrary, no evident variations in density are observed for GC samples in the different tested conditions, as also confirmed by the microstructural analysis (Figures $4 e-f$ vs Figures $6 c$ ). 


\begin{tabular}{|c|c|}
\hline Sample & $\begin{array}{l}\text { Density } \\
{\left[\mathrm{g} / \mathrm{cm}^{3}\right]}\end{array}$ \\
\hline AM as-produced & $2.678 \pm 0.007$ \\
\hline$A M 540^{\circ} \mathrm{C} 1 \mathrm{~h}-180^{\circ} \mathrm{C} 2 \mathrm{~h}$ & $2.623 \pm 0.005$ \\
\hline$A M 540^{\circ} \mathrm{C} 9 h-160^{\circ} \mathrm{C} 4 h$ & $2.573 \pm 0.006$ \\
\hline AM hip $-540^{\circ} \mathrm{C} 9 \mathrm{~h}-160^{\circ} \mathrm{C} 4 \mathrm{~h}$ & $2.661 \pm 0.001$ \\
\hline GC as-produced & $2.664 \pm 0.007$ \\
\hline$G C 540^{\circ} \mathrm{C} 1 \mathrm{~h}-180^{\circ} \mathrm{C} 2 \mathrm{~h}$ & $2.671 \pm 0.002$ \\
\hline$G C 540^{\circ} \mathrm{C} 9 h-160^{\circ} \mathrm{C} 4 h$ & $2.669 \pm 0.004$ \\
\hline
\end{tabular}

Table 3. Density results of $A M$ and GC samples.

\section{Impact properties}

In Figure 7, representative force-displacement curves are shown for each investigated condition of the AM samples, while the mean values and standard deviations of peak force, peak displacement, initiation energy and propagation energy are summarized in the graphs of Figure 8 .

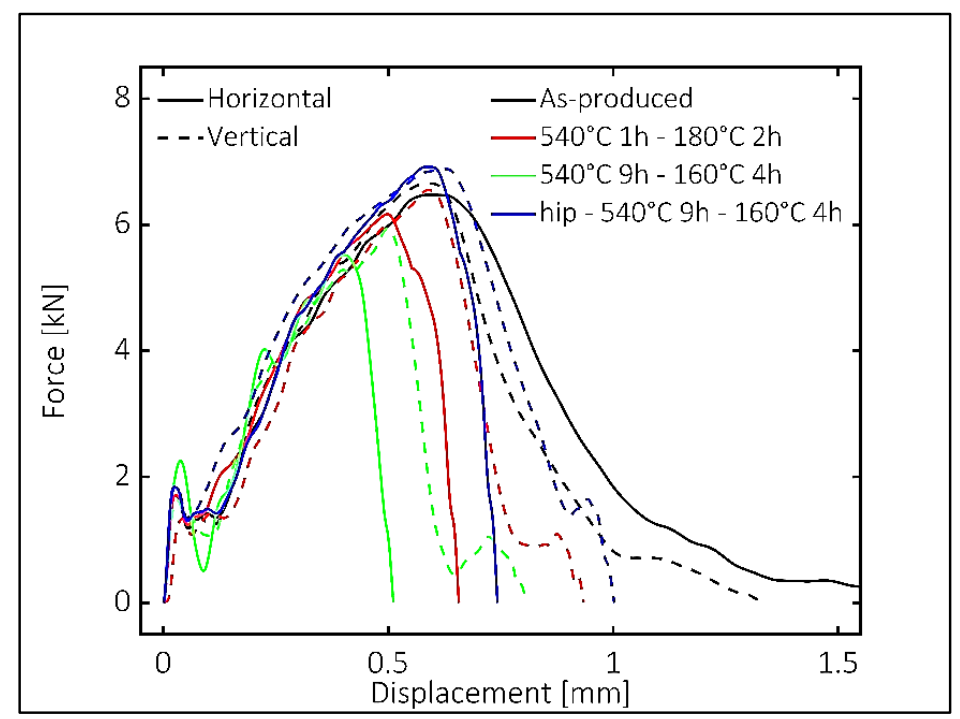

Fig. 7. Force-displacement curves from Charpy impact tests for AM samples in all investigated conditions. 


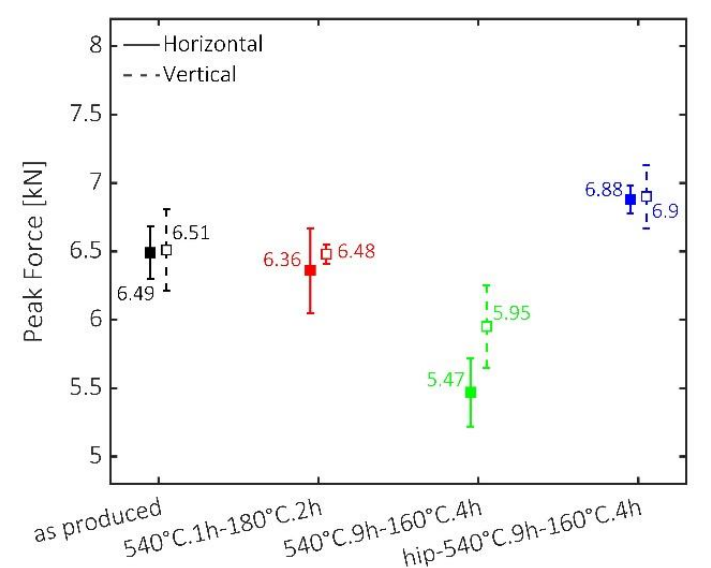

(a)

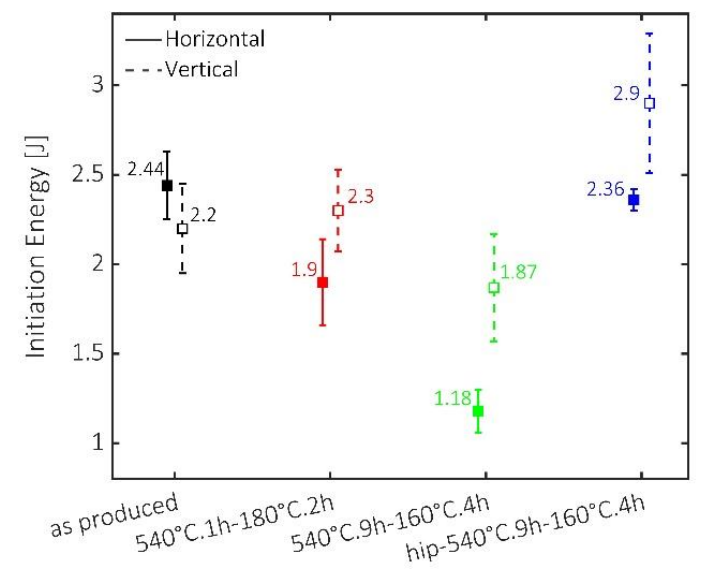

(c)

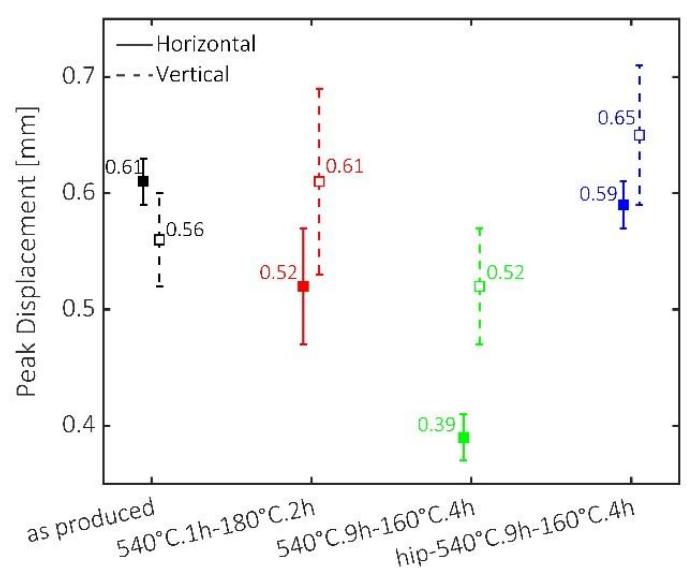

(b)

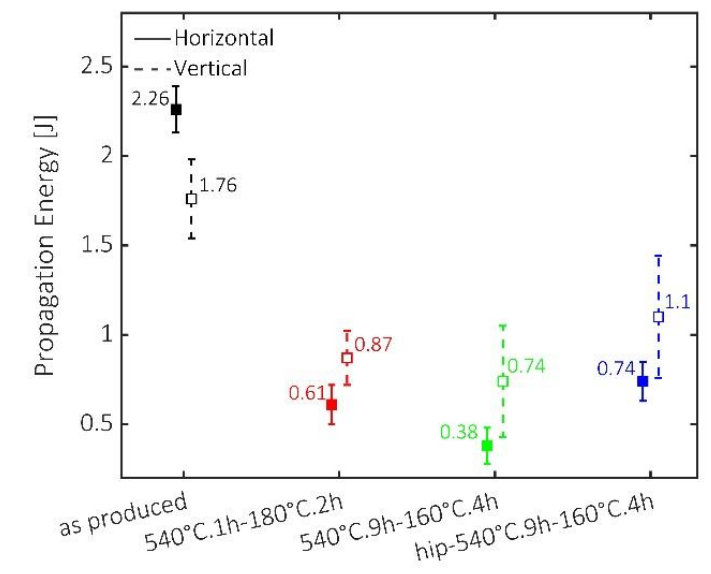

(d)

Fig. 8. Parameters from impact test for the AM samples: (a) peak force, (b) peak displacement, (c) initiation energy and $(d)$ propagation energy. Labelled points are the mean values and deviations are showed as error bars.

For the samples in the as-produced condition, no significant difference in the peak force can be detected for the two building orientations. This may be due to the very similar cellular microstructure which characterizes both samples in horizontal and vertical orientations (see Figures $\boldsymbol{4} \boldsymbol{a}-\boldsymbol{b})$, as well as to the absence of a pronounced texture. In fact, it has been reported [31] that using a non-monodirectional scanning strategy enables a reduction in the texture index of the material, resulting in almost isotropic strength. On the other hand, there is a small difference in the peak displacement and the curve for vertical samples falls to zero-force value in a shorter displacement range than that for the horizontal samples. This results in slightly higher values of initiation and propagation energy for horizontal samples as compared to vertical samples, suggesting a different deformation mechanism. Fractographic evaluations, which are discussed in the following section, are required to analyse the crack propagation and the failure mode in the two cases. 
The considered T6 treatments appear not to enhance the mechanical properties of the material, since peak force (Figure 8a) and impact energies (Figures 8c-d) are comparable or even lower than in the as-produced condition. As concerns the alloy in the $540^{\circ} \mathrm{C} 1 \mathrm{~h}-180^{\circ} \mathrm{C} 2 \mathrm{~h}$ condition, no significant differences in the peak force (Figure 8a) and initiation energy (Figure 8c) are detected as compared with the performance of as-produced samples, despite the different microstructure obtained after heat treatment (Figure 4). On the other hand, the propagation energy of samples in this and in the other heat-treated conditions is lower than in the as-produced sample. This is probably due to the change in microstructural feature after heat treatment, including the precipitation of the $\mathrm{Mg}_{2} \mathrm{Si}$ reinforcing phases and segregation of super-saturated $\mathrm{Si}$, as well as the enlargement of the gas pores $[24,28,35]$. All these phenomena could contribute to a reduction in deformation capability of the heat-treated material.

After a longer solution treatment, samples exhibit a more evident decrease in the impact properties as compared to both the as-produced and the other heat-treated conditions. Such occurrences could be due to the long-duration heat treatment, which may further affect the microstructure of the alloy. It should also be observed that, after each studied heat treatment, both initiation and propagation energies are higher for the vertically oriented samples than for the horizontal ones. This inversion of the trend previously described for the as-produced condition suggests a lower deformation capability of the horizontally produced samples. Analysis of the fracture surfaces and evaluation of the fracture mechanism will help to better understand this behaviour.

HIP appears to have a considerable beneficial effect on the mechanical properties of the alloy, probably thanks to its enclosure effect on porosity. It improves peak force even in comparison with the as-produced samples and causes a rise in peak displacement in both building orientations compared to the other heat-treated samples, thus also leading to an increase in the initiation energy. However, the propagation energy remains fairly similar to the other heat-treated conditions and in any case much lower than the as-produced condition.

In order to evaluate the different microstructures and fracture mechanisms, tests were also performed on samples produced by GC. Figure 9 displays the representative force-displacement curves for the GC samples, under all test conditions. All the parameters calculated from the Charpy impact tests are summarized in Figure 10. 


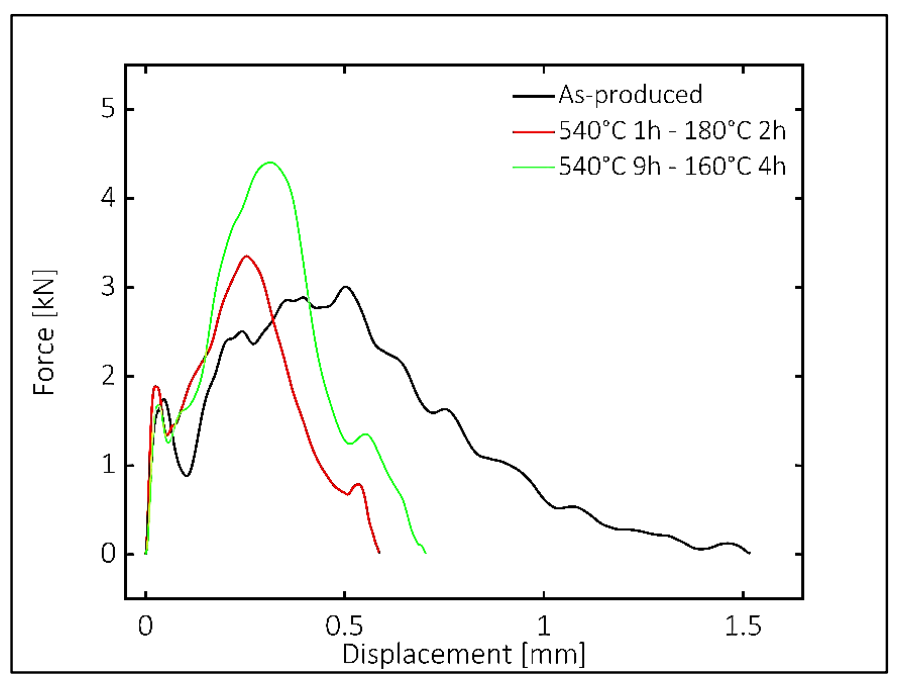

Fig. 9. Force-displacement curves from Charpy impact tests for GC samples under all investigated conditions.

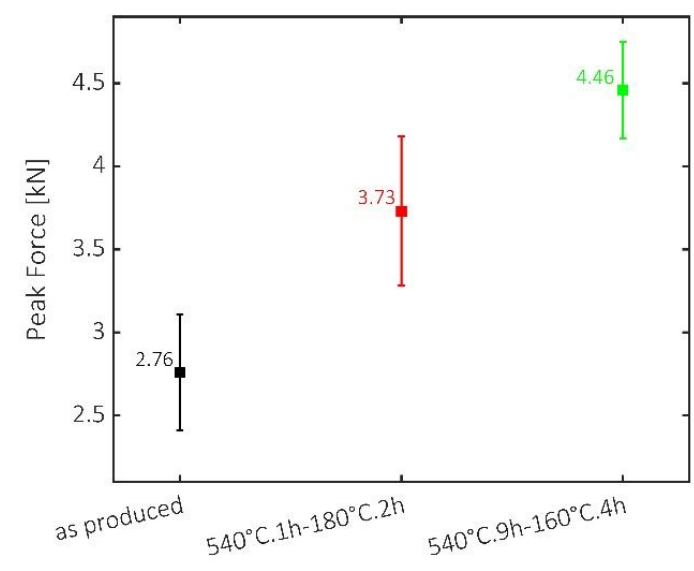

(a)

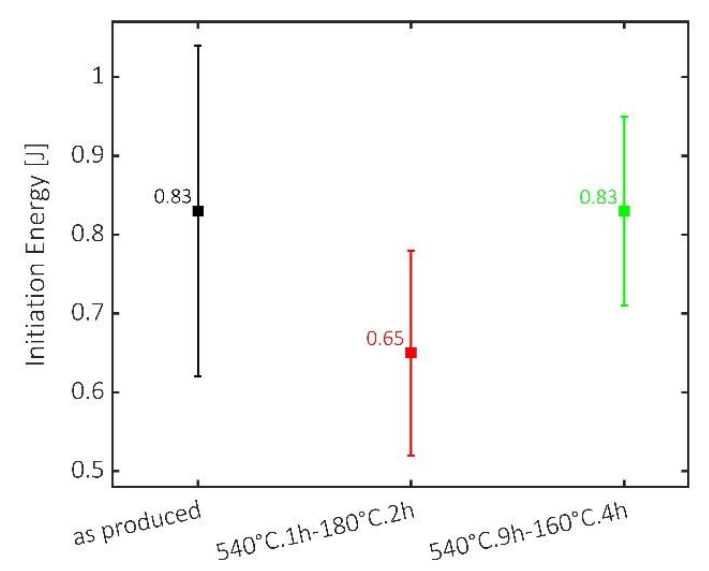

(c)

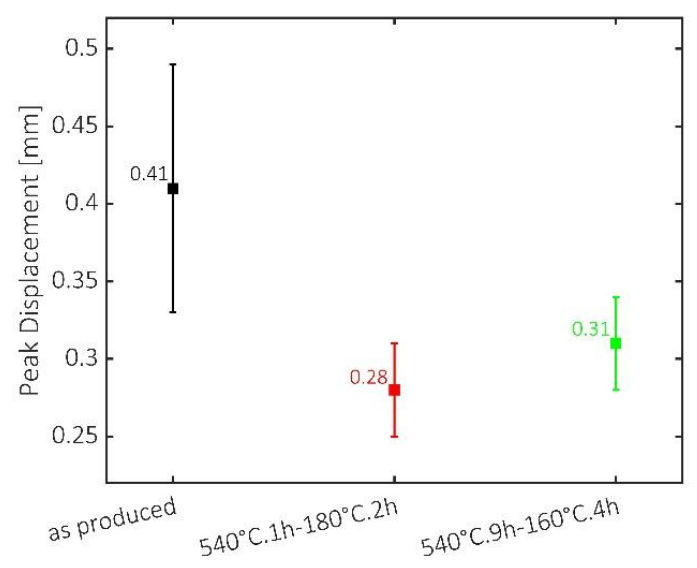

(b)

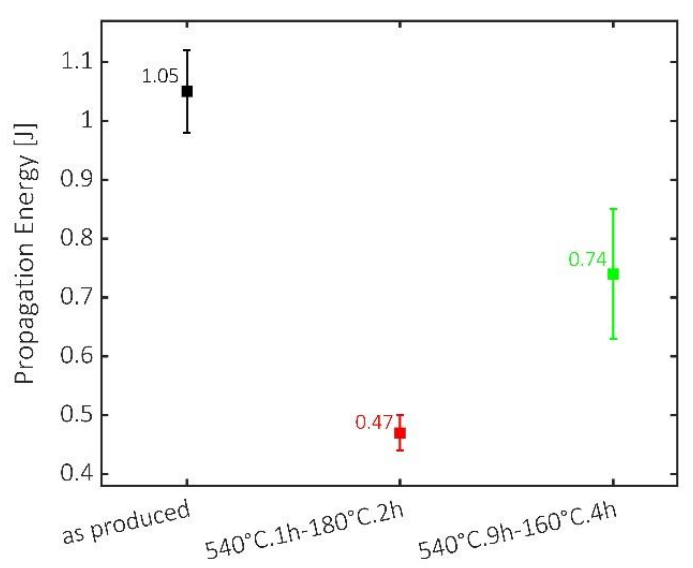

(d)

Fig. 10. Parameters from impact test for the GC samples: (a) peak force, (b) peak displacement, (c) initiation energy and (d) propagation energy. Labelled points are the mean values and standard deviations are showed as error bars. 
The peak force (Figure 9) for the alloy under the as-produced condition is lower compared to the others, implying lower mechanical properties. At the same time, the whole curve appears flatter, involving a greater range of displacements than for the $\mathrm{GC}$ heat treated ones and thus a higher amount of energy absorbed (Figures 10c-d), before and after the beginning of the fracture.

After both the applied heat treatments, an increase in peak force is observed due to the precipitation of reinforcing $\mathrm{Mg}_{2} \mathrm{Si}$ intermetallic compounds. As a drawback, this precipitation causes a considerable drop in the peak displacement, thus lower deformation capability. It is worth noticing that, despite the higher strength, no significant difference in the peak displacement can be observed for the $9 \mathrm{~h}$ - treated alloy as compared to the $1 \mathrm{~h}$ - treated one. Hence, the difference in the initiation energy is directly related to the peak force values. Nevertheless, the propagation energy of the alloy in the $540^{\circ} \mathrm{C} 9 \mathrm{~h}-160^{\circ} \mathrm{C} 4 \mathrm{~h}$ condition increases with respect to the $1 \mathrm{~h}$ - treated alloy. SEM analysis of fracture surfaces, presented in the following paragraph, was performed to produce evidence of this behaviour.

In general, under all conditions, the GC alloy appears less able to absorb the impact energy and to accommodate deformation, as compared to the performance of the AM samples. Therefore, the reasons for this difference in behaviour were investigated from a microstructural point of view.

\section{Microstructural evaluation of AM fracture profiles}

In order to provide a detailed description of the impact behaviour of the studied materials, in accordance with Figure 3, the fracture profiles of sections perpendicular to the notch of AM samples in the as-produced condition were observed for both building orientations. In the AM samples the fracture mainly propagates through the hatch overlaps, which are the weaker possible path. In fact, the hatch overlap zone, compared to the inner region of the melt pool, is characterized by both a coarser microstructure and a high amount of $\mathrm{Si}$ which is no longer in solid solution in the $\alpha-\mathrm{Al}$ phase, but instead segregated in the interdendritic regions $[24,33,35,60]$. Both these features provide an easier path for crack propagation. From a mechanical point of view, for samples loaded perpendicularly to the layers, the fracture plane would be parallel to the layers themselves. Hence, in an attempt to keep itself as far as possible along this plane and, at the same time, along the weaker path (hatch overlaps), the fracture propagates through the interface between adjacent layers, as reported in various studies $[30,33,35,61]$. This fracture path leads to the so-called layer-layer or inter-layer fracture, as reported in the sketch of Figure 11. 

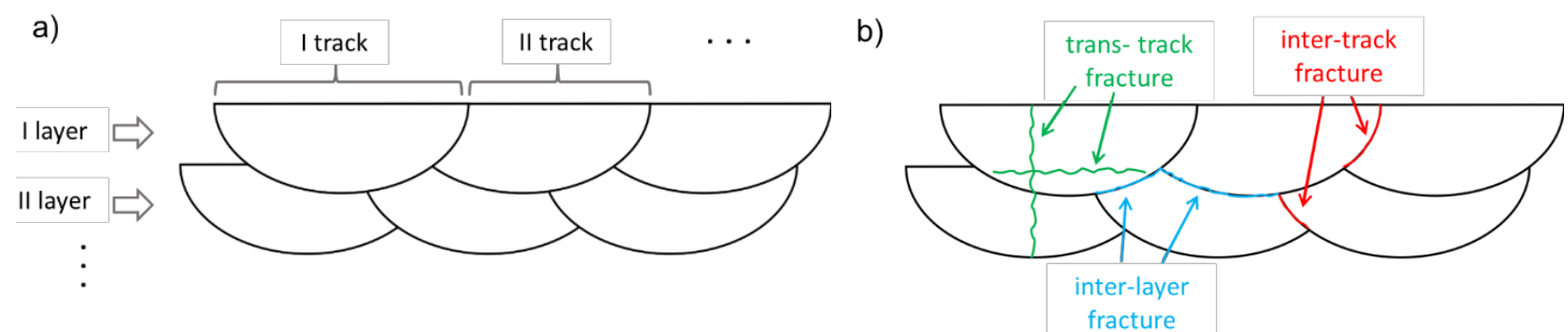

Fig. 11. Diagram of the fracture mechanisms

Such behaviour conforms to our vertically built samples (Figure 12a) even if sometimes the crack can also propagate through the inner part of the melt pool, causing a trans-track fracture. However, this mechanism is less commonly detected.

On the other hand, for AM samples loaded parallel to the layers, the fracture plane would be perpendicular to the layers themselves. Conversely, with the previous case, the fracture path therefore involves different hatch overlaps regions, leading to a mixed inter-track/inter-layer fracture. In addition, the fracture can also advance through the track core, leading to a trans-track fracture. In accordance with the literature $[30,33,35,61]$, in the horizontally built samples tested in this study (Figure 12b), the fracture involves both the interface between adjacent tracks or layers and the core of the tracks themselves, resulting in a mixed fracture mechanism, but preferentially a trans-track path. It is worth noticing that the crack path of vertical samples in as-produced condition would be relatively flat due to the flatness of the inter-layer hatch overlaps. On the contrary, the mixed fracture mechanism of the horizontal samples leads to a more tortuous crack path. This means that the vertical samples are able to accommodate lower deformation compared to the horizontal samples [33, 35], which may explain their smaller peak displacement values (Figure $8 \boldsymbol{b}$ ). On the other hand, no anisotropy was detected in the peak force, probably because of the nonmonodirectional scanning strategy which reduces the possible texture of the alloy [35]. Therefore, the different fracture path seems also to be responsible for the lower initiation (Figure 8c) and propagation energy (Figure $8 d$ ) of the vertically oriented samples as compared to the horizontal ones. 


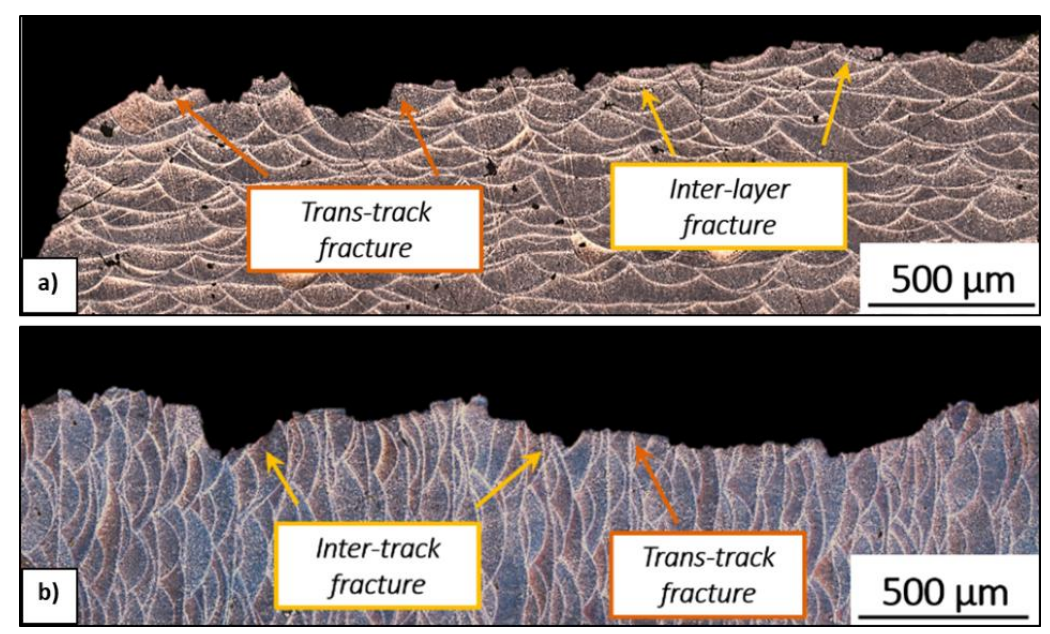

Fig. 12. Fracture profiles for AM samples in as-produced condition, perpendicular to the notch, in (a) vertical and (b) horizontal orientations.

\section{Microstructural evaluation of fracture surfaces}

Figure 13 shows the fracture surfaces of samples in as-produced condition for both horizontal and vertical orientations. The fracture surface of horizontally oriented samples (Figure 13a) is characterized by a 'step-like' morphology, with the presence of many variations in depth of the fracture plane together with other flatter areas. This can be attributed to a mix of inter-track and trans-track paths. The former enables the crack front to move both upward and downward with respect to the nominal fracture plane. The latter leaves on the fracture surface the characteristic semi-circular traces corresponding to the scan tracks, also detectable at higher magnification in Figure 13b. Some pores are also evident on the fracture surface (Figure 13a).

Figures $13 \boldsymbol{c}$-d show the fracture surface of the vertically orientated sample. Some small pores can be also detected in this case, but the overall aspect of the fracture surface is quite different and clearly flatter as compared to the previous one. In fact, given the inter-layer fracture path, some semi-cylindrical traces, corresponding to scan tracks detached during fracture propagation, are visible. Observation of these features also reveals the original scanning strategy.

The analysis of the fracture surfaces of the alloy in the as-produced conditions enables more indepth understanding and confirmation of the failure behaviour observed in the previous section, with the fracture path mainly involving the areas of weak hatch overlaps, but also the core of the melt pools. In addition, the more tortuous fracture path, which characterizes the horizontal produced samples rather the vertical ones, is clearly identifiable, as will be also confirmed in the fractal dimension analysis section. Such observations explain the anisotropic deformation behaviour for samples produced in different directions. This in turn, taking into account the almost isotropic strength of the material, explains the lower energy absorbed by vertical samples, both up to and 
after fracture. Similar behaviour has been previously reported for tensile tests [22, 26, 29, 31] and for fracture toughness tests [31].

At higher magnification (Figure 14), it is possible to detect a micro-dimples structure, with a very shallow morphology [62-63], and thus quite different from that typical of a cast alloy. The presence of this feature indicates a ductile behaviour for the alloy and thus a reasonable amount of energy absorbed during fracture.
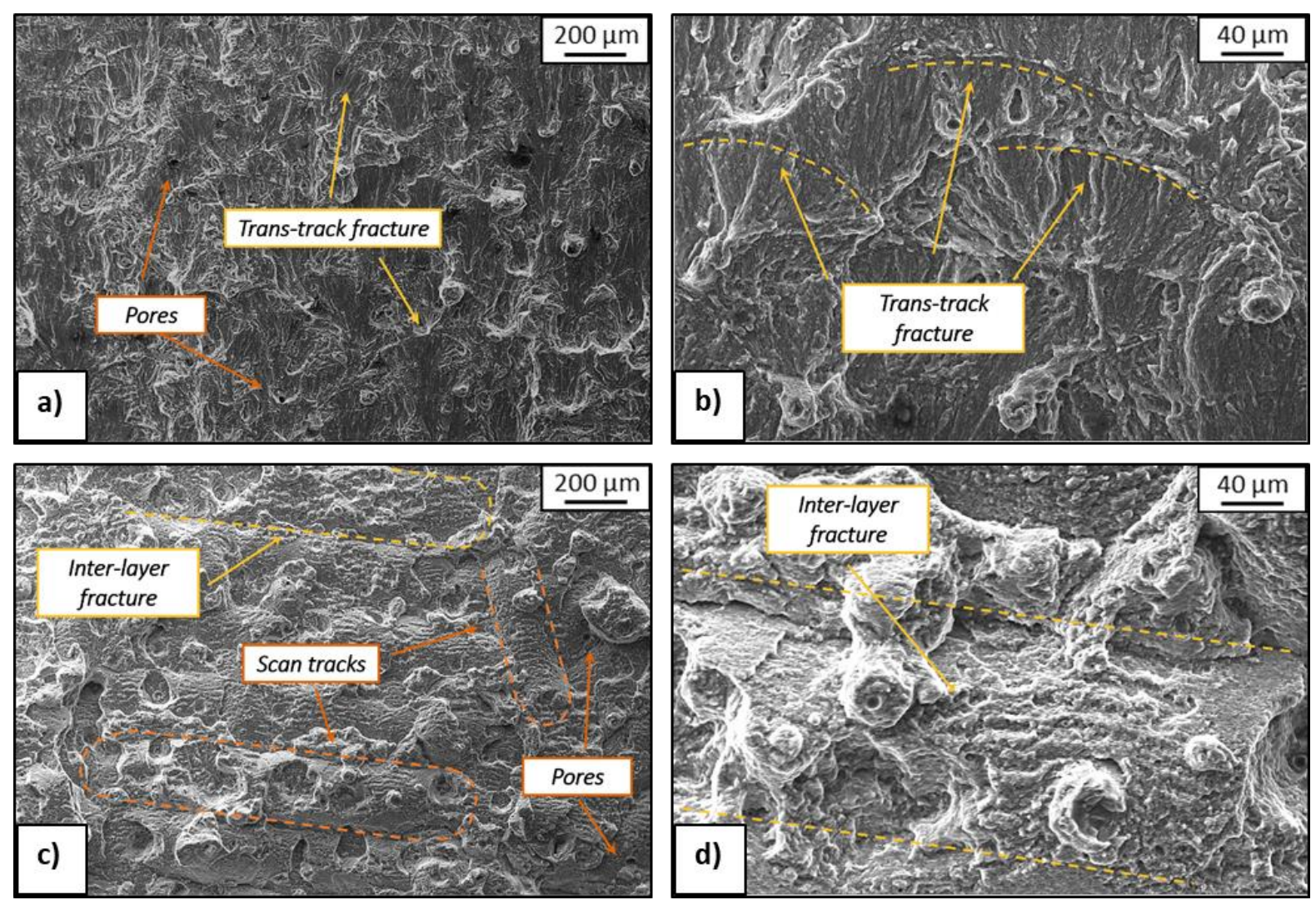

Fig. 13. Fracture surface for AM samples in as-produced condition, in $(a, b)$ horizontal and $(c, d)$ vertical orientations, at different magnification.
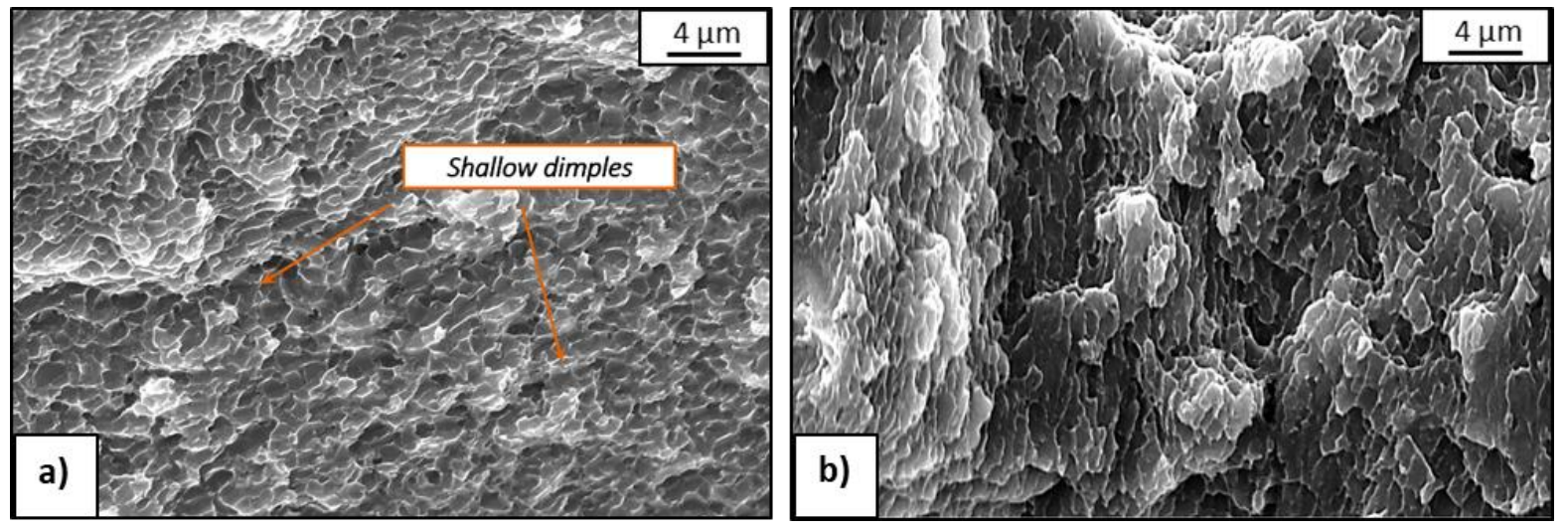

Fig. 14. Fracture surface for AM samples in as-produced condition, in (a) horizontal and (b) vertical orientations, at high magnification 
Figure 15 shows the fracture surfaces of samples in $540^{\circ} \mathrm{C} 1 \mathrm{~h}-180^{\circ} \mathrm{C} 2 \mathrm{~h}$ condition, for both horizontal and vertical orientations. In comparison with the as-produced samples, after heat treatment, the typical features of the AM fracture surfaces are barely detected. This is because the heat treatment causes the spheroidization of Si particles, thus leading to a rough appearance of the fracture surface. In addition the heat treatment causes also the enlargement of the gas pores and the interdendritic segregation of super-saturated $\mathrm{Si}$, no longer merely in hatch overlap regions, as in the as-produced condition, but also in the inner region of the melt pool. Both these outcomes cause the crack to deviate easily from its usual path, contributing to the formation of such an irregular surface. Nevertheless, some of the above-mentioned features, namely trans-track as well as some inter-layer fracture paths and scan lines, are still discernible in horizontal and vertical orientations, respectively.

This suggests that the fracture behaviour of the heat-treated samples is not significantly different from that of as-produced ones. Despite this, both initiation and, even more so, propagation energy decrease after heat treatment. Although not directly observable on the fracture surfaces, it has been already shown that heat treatment causes both the segregation of Si from aluminium phase $[24,28$, $35,60]$ and the precipitation of strengthening $\mathrm{Mg}_{2} \mathrm{Si}$ intermetallic compounds [24, 28]. These occurrences, together with the swelling of the gas pores detectable on the fracture surfaces in Figure 16, could explain the reduction of absorbed energy.

Anyway, it is worth noting that, contrary to the as-produced condition, the energy absorbed by vertical specimens is higher than the horizontal ones.

One possible reason could be the interdendritic segregation of $\mathrm{Si}$ over the entire melt pool area caused by the heat treatment. It has been reported that the directional solidification associated with the SLM processes induces texture along the $<100>$ direction, with $\alpha$-Al grains resulting mainly elongated towards the building direction [35]. Therefore, in vertically oriented samples, considering the previously observed inter-layer fracture path, the fracture advances mainly through the elongated $\alpha-\mathrm{Al}$ grains along their minor axis. On the contrary in horizontally oriented samples, considering the inter-track and trans-track fracture path, the fracture involves mainly the elongated grain boundaries. Hence, the interdendritic segregation of Si due to the heat treatment determines the embrittlement of the grain boundaries and a partial softening of the $\alpha$-Al grains, because of the existing precipitation of the $\mathrm{Mg}_{2} \mathrm{Si}$ phases. As a consequence, a smaller amount of energy is absorbed considering the fracture path of the horizontally oriented samples. A similar result has been reported by Suryawanshi et al. [35] considering the fracture toughness of Additive Manufactured samples, before and after heat treatment.

Additionally, a larger number of gas pores seems to appear on the fracture surface of the horizontal samples, as compared to the vertical ones. This may be due to the different location of the gas pores 
inside the melt pools. In fact, as previously shown in Figures $\mathbf{4} \boldsymbol{a}-\boldsymbol{b}$ for the as produced samples, it appears that the gas pores tend to be mainly located inside the melt pools and along the inter-track interfaces, rather than on the inter-layer interfaces. In the light of the previous discussion, this means that the fracture front will more probably encounter a gas pore along the fracture path of the horizontally oriented samples. Nevertheless, since in the as-produced condition the size of gas pores is quite small, there is no evident poisoning effect on the energy absorbed by the horizontally built samples as compared to the vertically built ones. Conversely, after the heat treatment, the swelling of gas pores increases the fraction of voids that the crack encounters along its path, reducing the absorbed energy to a greater extent for horizontal samples.

As shown in Figures 15a-b, both horizontal and vertical samples exhibit a ductile fracture mode, as suggested by the presence of dimples.
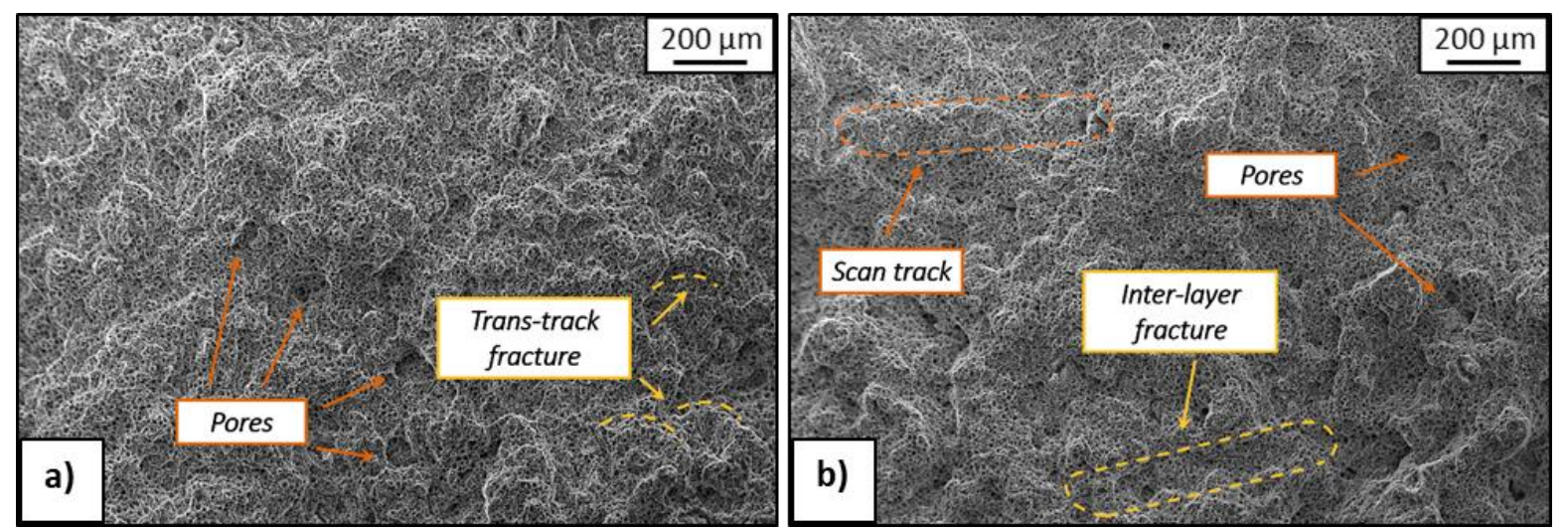

Fig. 15. Fracture surface for AM samples in $540^{\circ} \mathrm{C} \mathrm{h} \mathrm{h}-180^{\circ} \mathrm{C} 2 \mathrm{~h}$ condition, in (a) horizontal and (b) vertical orientations.

Figure 16 shows the fracture surfaces of samples in $540^{\circ} \mathrm{C} 9 \mathrm{~h}-160^{\circ} \mathrm{C} 4 \mathrm{~h}$ condition, for both horizontal and vertical orientations. As in the previous case, some typical features of the asproduced condition are still detectable, as well as the higher number of gas pores emerging on the surface of horizontally oriented samples. In any case, as compared to samples subjected to $1 \mathrm{~h}$ lasting treatment, the unevenness of the fracture surface further increases. As reported above, this is probably due to the longer duration of the heat treatment, which promotes further swelling of both the Si particles, leading to the larger dimples detectable on the surfaces in Figure 13, and the gas pores, facilitating possible large deviations in the crack path. The enlargement of the gas pores clearly visible in Figure 16 conforms to the density analysis shown in Table $\mathbf{3}$ where, among the considered samples, the sample in the $540^{\circ} \mathrm{C} 9 \mathrm{~h}-160^{\circ} \mathrm{C} 4 \mathrm{~h}$ condition has the lowest value. Since no other remarkable differences were highlighted in comparison with the previous case, the swelling of the gas pores is recognized as the main cause for the worsening of the impact properties in the case 
of long-time treated alloy. In fact, it reduces the bearing section area of the specimens and creates very favourable sites for crack propagation, resulting in the further decrease of peak force, initiation energy and propagation energy respectively.
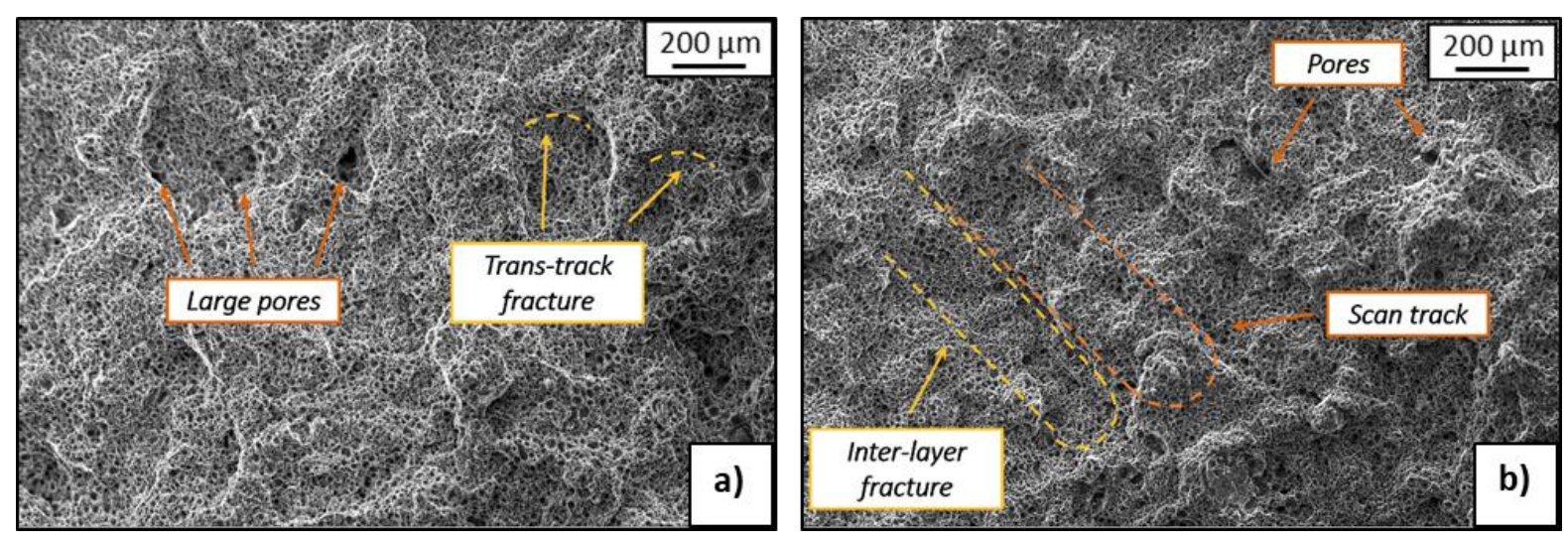

Fig. 16. Fracture surface for AM samples in $540^{\circ} \mathrm{C} 9 \mathrm{~h}-160^{\circ} \mathrm{C}$ 4h condition, in (a) horizontal and (b) vertical orientations.

In Figure 17, the fracture surfaces of samples in HIP $-540^{\circ} \mathrm{C} 9 \mathrm{~h}-160^{\circ} \mathrm{C}$ 4h condition, for both horizontal and vertical orientations, are shown. The overall unevenness of the surfaces is comparable to that of the alloy in the $540^{\circ} \mathrm{C} 9 \mathrm{~h}-160^{\circ} \mathrm{C} 4 \mathrm{~h}$ condition, whose larger gas pores are however no longer visible, suggesting that the HIP treatment successfully led to their enclosure. Detailed analysis of the fracture surfaces of these samples highlights the fact that the main difference with regard to the specimens that underwent different heat treatments is the nearly total absence of large gas pores, even if some very small pores are still detectable in both samples. In the light of these observations it could be suggested that the enhancement of impact properties of HIPtreated samples is therefore mainly related to the disappearance of the previously observed gas pores. It is worth noting that, even if both the peak force and the initiation energy benefit from the HIP process, thanks to the recovery of the bearing section area, this is no longer valid for the propagation energy. In fact, it remains largely lower than in the as-produced condition, because of the embrittlement effect of both the precipitation strengthening of the $\mathrm{Mg}_{2} \mathrm{Si}$ and the interdendritic segregation of Si. 

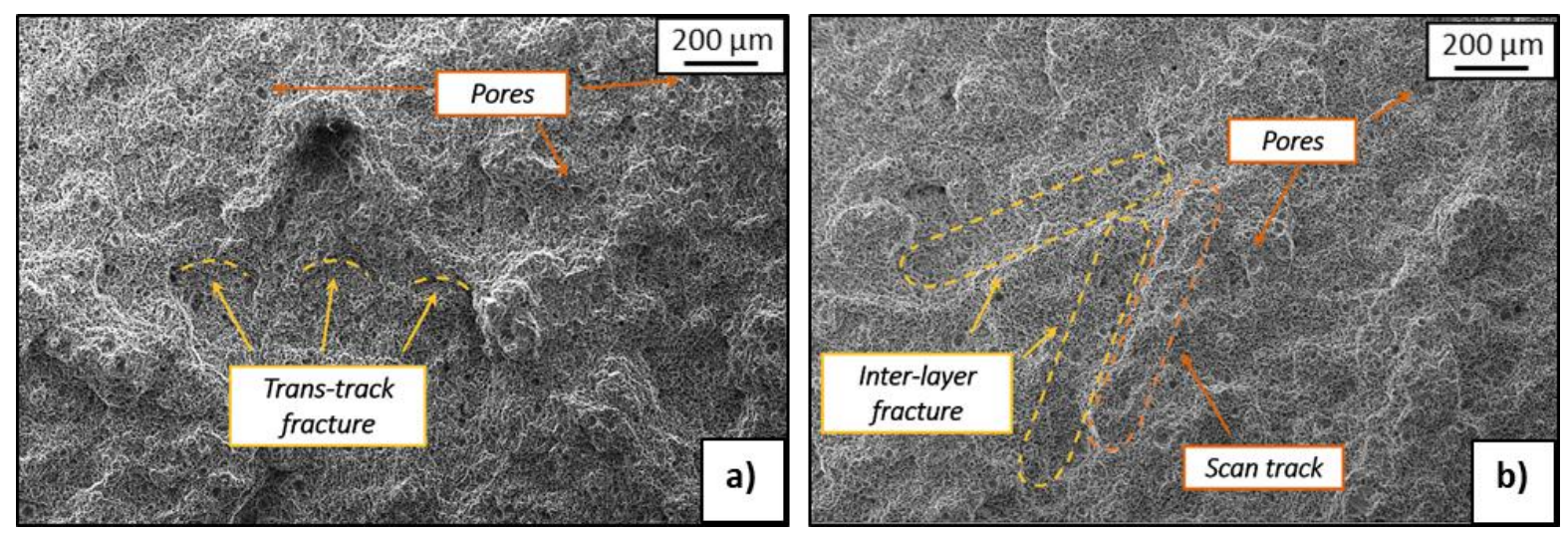

Fig. 17. Fracture surface for AM samples in hip $-540^{\circ} \mathrm{C} 9 \mathrm{~h}-160^{\circ} \mathrm{C} 4 \mathrm{~h}$ condition, in (a) horizontal and (b) vertical orientations.

Figure 18 shows the fracture surfaces of the GC samples. In the as-produced condition (Figures $18 \boldsymbol{a}-\boldsymbol{b})$, fracture occurs mainly at the interface between the primary $\alpha$-Al dendrites, sometimes detectable on the fracture surface, and the eutectic phase, leading to an inter-dendritic fracture mode. In addition, shrinkage porosities, including the emerging tips of the dendrite arms, are visible on the fracture surface. At higher magnification (Figure 18b), the debonding of the aluminium phase from the platelet-like Si particles can be detected. Besides this, the overall aspect of the fracture surface is clearly ductile, thus explaining the high amount of energy absorbed before and after fracture.

Considering the alloy in the $540^{\circ} \mathrm{C} 1 \mathrm{~h}-180^{\circ} \mathrm{C} 2 \mathrm{~h}$ condition, the precipitation of the reinforcing intermetallic compounds strengthens the aluminium phase and makes it more prone to cleavage, as detectable in Figures 18c-d, where some eutectic grains appear to be fractured along specifically oriented planes. The embrittlement of the material due to the ageing treatment seems therefore to be responsible for the decrease in initiation energy and even more so in propagation energy as compared to the as-produced condition (Figure 10c-d). In addition, the presence on the fracture surface of some Si particles still exhibiting lamellar morphology suggests that they have not undergone complete spheroidization during the $1 \mathrm{~h}$ heat treatment. Such evidence could reasonably explain the lower amount of absorbed energy compared to the other heat-treated condition.

Taking into account the alloy in the $540^{\circ} \mathrm{C} 9 \mathrm{~h}-160^{\circ} \mathrm{C} 4 \mathrm{~h}$ condition (Figures 18e-f), there is a visible combination of the previously described failure mechanisms, since either the inter-dendritic fracture of $\alpha-\mathrm{Al}$ dendrites or the cleavage of eutectic grains appears on the fracture surface. In addition, at higher magnification, the more ductile behaviour of the alloy compared to the others can be detected. In fact, many large-dimples areas are visible on the surface, meaning that the $9 \mathrm{~h}$ heat treatment led to improved spheroidization of the Si particles. This promotes alloy deformation, leading to a higher amount of the energy absorbed up to fracture (Figure 10d). The different 
microstructural properties of GC alloy had a clear effect on the impact behaviour as compared to the AM samples. Interestingly, the inter-dendritic fracture mechanism typical of cast alloys is less able to absorb impact energy than either the trans-track or the inter-layer fracture identified as the main mechanisms for as-produced AM alloy. Even after heat treatment, dimples size is significantly smaller for AM samples, resulting in a higher energy required for crack propagation as compared to the GC alloy.
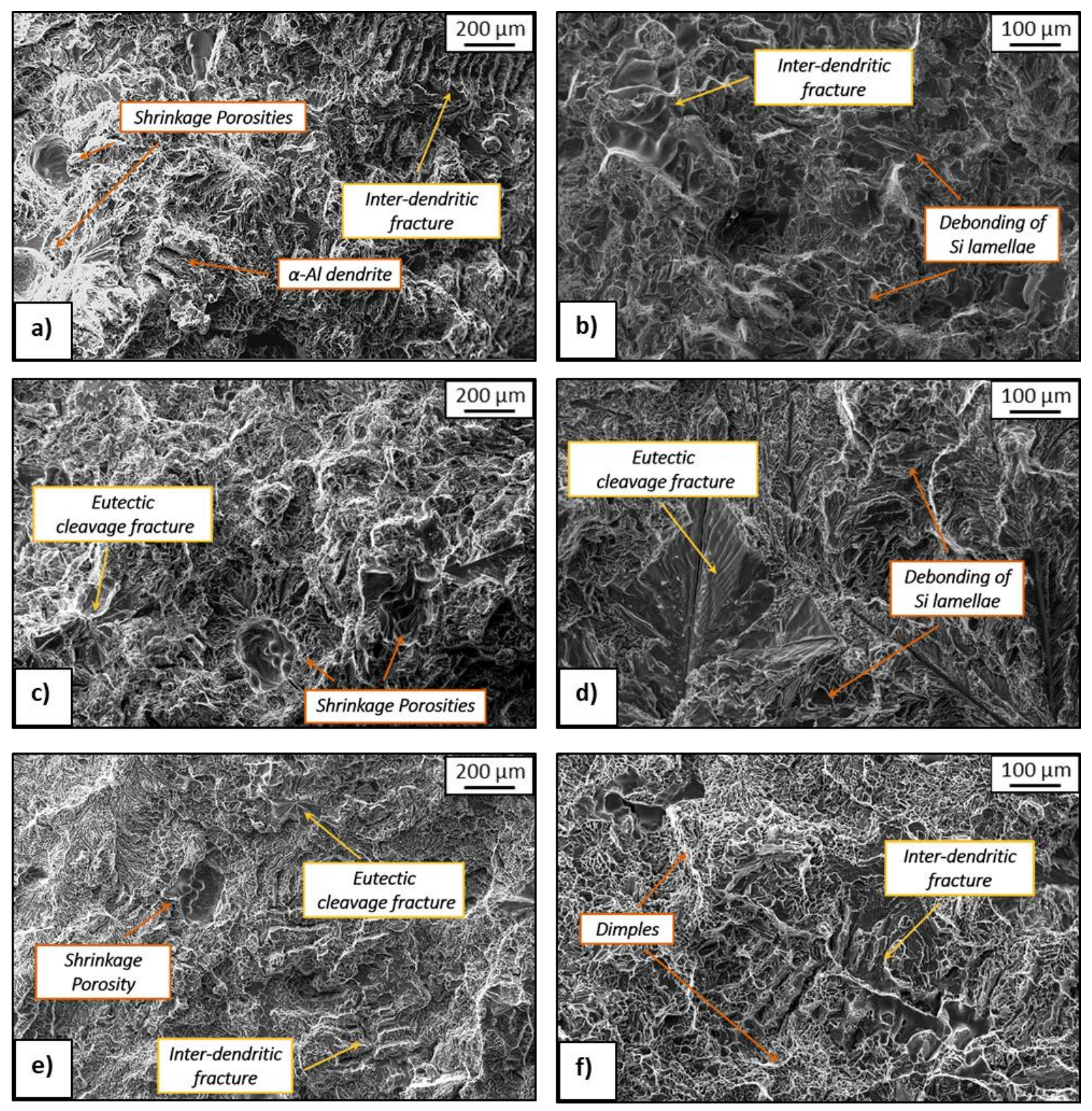

Fig. 18. Fracture surface for GC samples in (a, b) as-produced, $(c, d) 540^{\circ} \mathrm{C} 1 \mathrm{~h}-180^{\circ} \mathrm{C} 2 \mathrm{~h}$ and (e, f) $540^{\circ} \mathrm{C} 9 \mathrm{~h}-160^{\circ} \mathrm{C} 4 \mathrm{~h}$ conditions, at different magnification. 


\section{Fractal dimension analysis}

In order to carry out a quantitative evaluation of the fracture surfaces of the AM samples, the fractal dimension of the surfaces themselves was calculated using a non-contact 3D optical profilometer and a tailored Matlab ${ }^{\circledR}$ code. Figure 19 shows the mean values and the standard deviations (expressed as error bars) of the fractal dimension for specimens in both horizontal and vertical directions, for each treatment condition of the alloy. The fractal dimension for the alloy in the asproduced condition is higher for horizontally oriented specimens, as compared to vertical ones. This may be due to the different crack path in the two cases. In fact, as previously shown in Figure 12, for horizontally built specimens, the fracture occurs along the interfaces between adjacent tracks and through the track core, while it occurs at the interface between consecutive layers and sometimes through the track core for vertically built specimens. The former, as reported in the literature $[30,33,35,61]$, is characterized by a greater unevenness than the latter, thus leading to a higher fractal dimension. Considering the alloy in the $540^{\circ} \mathrm{C} 1 \mathrm{~h}-180^{\circ} \mathrm{C} 2 \mathrm{~h}$ condition, it can be seen that the fractal dimension increases as compared to the previous one, regardless of the building direction.

The microstructural changes induced by the heat treatment, i.e. the fragmentation and spheroidization of Si particles, as well as the formation of larger gas pores, could cause the fracture to deviate from its usual path, as previously observed in Figure 15a.

This suggestion may also explain the additional increase in the fractal dimension in the case of the 9 $\mathrm{h}$ - treated alloy, which exhibits larger dimples and gas pores on its fracture surface, as shown in Figures 16a-b. The fractal dimension does not change after HIP. This can be explained by considering the fracture surfaces in Figure 18. In fact, even though the HIP treatment caused a reduction of most of gas and lack-of-fusion pores, several smaller pores are still detectable on the surfaces. Such small pores together with the spheroidization of $\mathrm{Si}$, contribute to the fractal dimension remaining comparable to the $9 \mathrm{~h}$ - treated alloy. It is worth noting that, for each alloy condition, the fractal dimension of the horizontally built specimens is always higher than for the vertically built ones. Since in the as-produced condition this can be explained by the different fracture path in the two cases, it suggests that, in the heat-treated samples, the main fracture path remains the same, even if it sometimes deviates from its usual path. 


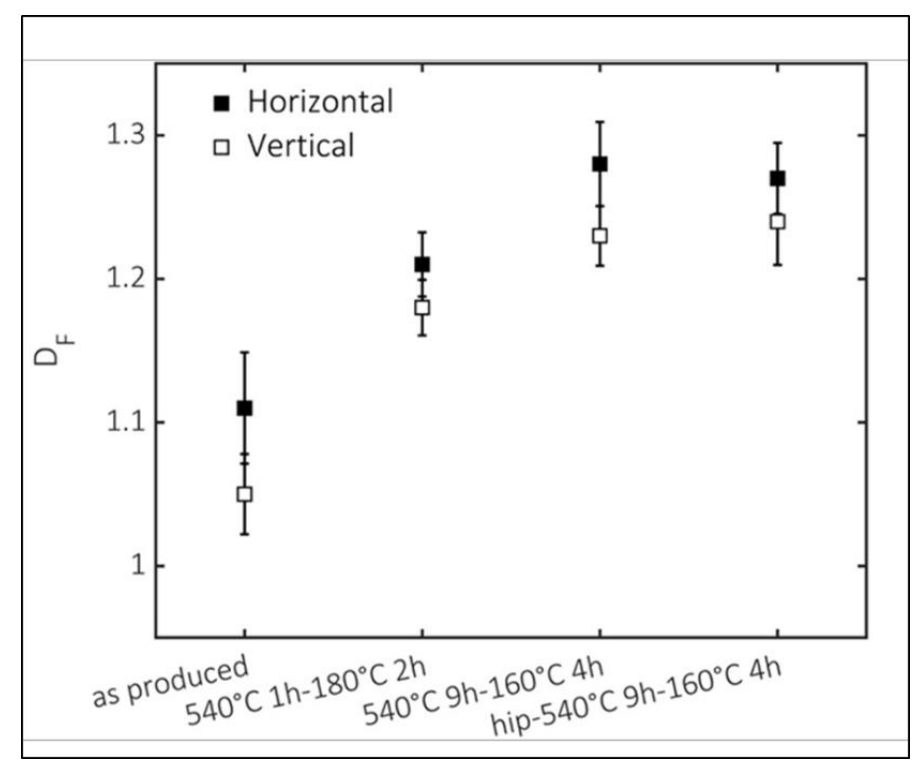

Fig. 19. Fractal dimension of the fracture profiles perpendicular to the notch, for each tested condition of AM alloys. Standard deviations are shown as error bars.

\section{Conclusions}

This study involves the systematic investigation on the impact behaviour of additive manufacturing and gravity casting AlSi10Mg samples in as-produced and heat-treated conditions performed using an instrumented Charpy pendulum. The results were correlated to the microstructural features under the various test conditions.

As-produced AM samples exhibited the best performance due to the peculiar microstructure, which played a major role in the fracture propagation mechanism. A mixed trans-track and hatch overlap regions mechanism was identified for horizontally built samples; while for vertically built samples, the crack propagation followed mainly an inter-layer fracture path. Correlation with the impact properties-leads to the conclusion that the fracture mechanism of the horizontal samples, thanks to its more tortuous path, enables greater deformation and thus the absorption of a larger amount of energy as compared to the vertical samples. In addition, the different fracture mechanism resulted in a higher unevenness of the surface for samples produced in the horizontal direction rather than in the vertical direction, also confirmed by the fractal dimension calculated using a non-contact $3 \mathrm{D}$ optical profilometer. Interestingly, this trend was still detectable after heat treatment, although to a lesser degree, meaning that the building direction has a clear effect on material properties despite the dissolution of the cellular microstructure after heat treatment. The fracture mechanism after heat treatment was also influenced by the presence of coarser brittle Si particles, mainly segregated in the interdendritic regions, and higher gas porosity, both representing a favourable path for the crack 
propagation and resulting in an overall decrease of impact strength. Consequently, the reduction of porosity due to HIP treatment leads to a certain improvement of the material performance, even though some porosities are still present. In comparison with the GC samples, AM material exhibited a much greater ability to absorb impact energy and to accommodate the corresponding deformation. The T6 heat treatment had the opposite effect on the materials produced with different technologies, enhancing the properties of GC samples, while reducing those of the AM alloy. These results also confirm the importance of both the definition and the improvement of proper heat treatment routes specifically tailored for AM materials, in order to exploit the remarkable properties in as-produced condition.

\section{Acknowledgments}

The authors wish to acknowledge M. Gelfi, Dept. of Mechanical and Industrial Engineering of the University of Brescia, for the contribution in samples microstructural analysis, F. Peli and A. Coffetti, Dept. of Mechanical and Industrial Engineering of the University of Brescia, for their support in Charpy samples preparation, and Ghial S.p.A., for providing the gravity cast samples.

\section{References}

[1] D. Herzog, V. Seyda, E. Wycisk, C. Emmelmann, "Additive manufacturing of metals", Acta Materialia, vol. 117, pp. 371-392, 2016.

[2] E. Olakanmi, R. Cochrane, K. Dalgarno, "A review on selective laser sintering/melting (SLS/SLM) of aluminium alloy powders: Processing, microstructure, and properties”, Progress in Materials Science, vol. 74, p. 401-477, 2015.

[3] N. Guo, M. C. Leu, "Additive manufacturing: technology, applications and research needs", Frontiers of Mechanical Engineering, vol. 8(3), p. 215-243, 2013.

[4] X. Wang, S. Xu, S. Zhou, W. Xu, M. Leary, P. Choong, M. Qian, M. Brandt, Y. Xie, "Topological design and additive manufacturing of porous metals for bone scaffolds and orthopaedic implants: A review", Biomaterials, vol. 83, pp. 127-141, 2016.

[5] L.E. Murr, "Frontiers of 3D Printing /Additive Manufacturing: from Human Organs to Aircraft Fabrication”, Journal of Material Science \& Technology, vol. 32, pp. 987-995, 2016.

[6] S. Sing, J. An, W. Yeong, F. Wiria, "Laser and electron-beam powder-bed additive manufacturing of metallic implants: A review on processes, materials and designs", Journal of Orthopaedic Research, vol. 34, n. 3, pp. 369-385, 2016.

[7] C. Yap, C. Chua, Z. Dong, Z. Liu, D. Zhang, L. Loh, S. Sing, "Review of selective laser melting: Materials and applications", Applied Physics Reviews, vol. 2-4, p. 041101, 2015. 
[8] S. Tofail, E. Koumoulos, A. Bandyopadhyay, S. Bose, L. O’Donoghue, C. Charitidis, "Additive manufacturing: scientific and tecnological challenges, market uptake and opportunities", Materials Today, vol. 21, n. 1, pp. 22-37, 2018.

[9] E. Atzeni, A. Salmi, "Economics of additive manufacturing for end-usable metal parts", The International Journal of Advanced Manufacturing Technology, vol. 62, n. 9-12, pp. 1147-1155, 2012.

[10] T. DebRoy, H. Wei, J. Zuback, T. Mukherjee, J. Elmer, J. Milewski, A. Beese, A. Wilson-Heid, A. De, W. Zhang, "Additive manufacturing of metallic components - Process, structure and properties", Progress in Materials Science, vol. 92, pp. 112-224, 2018.

[11] I. Tolosa, F. Garciandía, F. Zubiri, "Study of mechanical properties of AISI 316 stainless steel processed by "selective laser melting", following different manufacturing strategies", The International Journal of Advanced Manufacturing Technology, vol. 51, n. 5-9, p. 639-647, 2010.

[12] K. Guan, Z. Wang, M. Gao, X. Li, X. Zeng, "Effects of processing parameters on tensile properties of selective laser melted 304 stainless steel”, Materials and Design, vol. 50, pp. 581-586, 2013.

[13] B. Vrancken, L. Thijs, J.-P. Kruth, J. Van Humbeeck, "Heat treatment of Ti6Al4V produced by Selective Laser Melting: Microstructure and mechanical properties", Journal of Alloys and Compounds, vol. 541, n. 15, pp. 177-185, 2012.

[14] X. Gong, T. Anderson, K. Chou, "A study of the microstructural evolution during selective laser melting of Ti-6Al-4V", in ASME/ISCIE 2012 International Symposium on Flexible Automation, Louis, MO; United States, 2012.

[15] Q. Jia, D. Gu, "Selective laser melting additive manufacturing of Inconel 718 superalloy parts: Densification, microstructure and properties", Journal of Alloys and Compounds, vol. 585, pp. 713-721, 2014.

[16] P. Kanagarajah, F. Brenne, T. Niendorf, H. Maier, "Inconel 939 processed by selective laser melting: Effect of microstructure and temperature on the mechanical properties under static and cyclic loading", Materials Science and Engineering A, vol. 588, pp. 188-195, 213.

[17] E. Louvis, P. Fox, C. Sutcliffe, "Selective laser melting of aluminium components", Journal of Materials Processing Technology, vol. 211, n. 2, pp. 275-284, 2011.

[18] L. Thijs, K. Kempen, J.-P. Kruth, J. V. Humbeeck, "Fine-structured aluminium products with controllable texture by selective laser melting of pre-alloyed AlSi10Mg powder", Acta Materialia, vol. 61, p. 1809-1819, 2013.

[19] N.T. Aboulkhair, N. Everitt, I. Ashcroft, C. Tuck, "Reducing porosity in AlSi10Mg parts processed by selective laser melting”, Additive Manufacturing, vol. 1, pp. 77-86, 2014.

[20] T. Kimura, T. Nakamoto, M. Mizuno, H. Araki, "Effect of silicon content on densification, mechanical and thermal properties of Al-xSi binary alloys fabricated using selective laser melting", Materials Science and Engineering A, vol. 682, pp. 593-602, 2017.

[21] A. Aversa, M. Lorusso, G. Cattano, D. Manfredi, F. Calignano, E. Ambrosio, S. Biamino, P. Fino, M. Lombardi, P. Pavese, "A study of the microstructure and the mechanical properties of an Al-Si-Ni alloy produced via selective laser melting”, Journal of Alloys and Compounds, vol. 695, pp. 1470-1478, 2017. 
[22] X. Li, G. Ji, Z. Chen, A. Addad, Y. Wu, H. Wang, J. Vleugels, J. Van Humbeeck, J. Kruth, "Selective laser melting of nano-TiB2 decorated AlSi10Mg alloy with high fracture strength and ductility", Acta Materialia, vol. 129, pp. 183-193, 2017.

[23] J. Davis, ASM Speciality Handbook, Aluminum and Aluminum Alloys, Materials Park, OH: ASM International, Davis \& Associates, 1993.

[24] N. Aboulkhair, I. Maskery, C. Tuck, I. Ashcroft, N. Everitt, "The microstructure and mechanical properties of selectively laser melted AlSi10Mg: the effect of a conventional T6-like heat treatment", Materials Science and Engineering A, vol. 667, pp. 139-146, 2016.

[25] E. Brandl, U. Heckenberger, V. Holzinger, D. Buchbinder, “Additive manufactured AlSi10Mg samples using Selective Laser Melting (SLM): Microstructure, high cycle fatigue, and fracture behavior", Materials and Design, vol. 34, pp. 159-169, 2012.

[26] K. Kempen, L. Thijs, J. Van Humbeeck, J.-P. Kruth, "Mechanical properties of AlSi10Mg produced by Selective Laser Melting", Physics Procedia, vol. 39, pp. 439-446, 2012.

[27] J. Wu, X. Wang, W. Wang, M. Attallah, M. Loretto, "Microstructure and strength of selectively laser melted AlSi10Mg", Acta Materialia , vol. 117 , pp. 311-320, 2016.

[28] N. T. Aboulkhair, C. Tuck, I. Ashcroft, I. Maskery, N. M. Everitt, "On the precipitation hardening of selective laser melted AlSi10Mg", Metallurgical and Materials Transactions A, vol. 46A, pp. 3337-3341, 2015.

[29] N. Read, W. Wang, K. Essa, M. Attallah, "Selective laser melting of AlSi10Mg alloy: Process optimisation and mechanical properties development", Materials and Design, vol. 65, pp. 417-424, 2015.

[30] I. Rosenthal, A. Stern, N. Frage, "Microstructure and Mechanical Properties of AlSi10Mg Parts Produced by the Laser Beam Additive Manufacturing (AM) Technology", Metallography, Microstructure, and Analysis, vol. 3, n. 6, pp. 448-453, 2014.

[31] M. Krishnan, E. Atzeni, R. Canali, F. Calignano, D. Manfredi, E. Ambrosio, L. Iuliano, "On the effect of process parameters on properties of AlSi10Mg parts produced by DMLS", Rapid Prototyping Journal, vol. 20, n. 6, pp. 449-458, 2014.

[32] K. Kempen, L. Thijs, J. Humbeeck, J.-P. Kruth, "Processing AlSi10Mg by selective laser melting: Parameter optimisation and material characterisation", Materials Science and Technology, vol. 31, n. 8, pp. 917-923, 2015.

[33] I. Rosenthal, A. Stern, N. Frage, "Strain rate sensitivity and fracture mechanism of AlSi10Mg parts produced by Selective Laser Melting”, Materials Science and Engineering A, vol. 682, pp. 509-517, 2017.

[34] T. Mower, M. Long, "Mechanical behavior of additive manufactured, powder-bed laser-fused materials", Materials Science and Engineering A, vol. 651, pp. 198-213, 2016.

[35] J. Suryawanshi, K. Prashanth, S. Scudino, J. Eckert, O. Prakash, U. Ramamurty, "Simultaneous enhancements of strength and toughness in an Al-12Si alloy synthesized using selective laser melting", Acta Materialia, vol. 115, pp. 285-294, 2016.

[36] L. Girelli, M. Tocci, L. Montesano, M. Gelfi, A. Pola, "Investigation of cavitation erosion resistance of AlSi10Mg alloy for additive manufacturing”, Wear, Vol. 402-403, pp. 124-136, 2018. 
[37] L. Girelli, M. Tocci, L. Montesano, M. Gelfi, A. Pola, "Optimization of heat treatment parameters for additive manufacturing and gravity casting AlSi10Mg alloy", IOP Conference Series: Materials Science and Engineering, vol. 264, pp. 1-8, 2017.

[38] M.-W. Wu, P.-H. Lai, J.-K. Chen, "Anisotropy in the impact toughness of selective laser melted Ti6Al-4V alloy", Materials Science and Engineering A, vol. 650, pp. 295-299, 2016.

[39] G. Puppala, A. Moitra, S. Sathyanarayanan, R. Kaul, G. Sasikala, R. Prasad, L. Kukreja, "Evaluation of fracture toughness and impact toughness of laser rapid manufactured Inconel-625 structures and their corelation", Materials and Design, vol. 59, pp. 509-515, 2014.

[40] E. Yasa, J. Deckers, J.-P. Kruth, M. Rombouts, J. Luyten, "Charpy impact testing of metallic selective laser melting parts", Virtual and Physical Prototyping, vol. 5, n. 2, pp. 89-98, 2010.

[41] EOS GmbH Electro Optical System, [Online]. Available: http://www.eos.info/eos-m290.

[42] EOS GmbH Electro Optical System, [Online]. Available: https://www.eos.info/material-m.

[43] EN, EN AC 43200, EN 1706 (2010) Aluminium and aluminium alloys - Castings - Chemical composition and mechanical properties.

[44] F. Kim, S. Moylan, "Literature Review of Metal Additive Manufacturing Defects", Advanced Manufacturing Series (NIST AMS) - 100-16, https://doi.org/10.6028/NIST.AMS.100-16, 2018.

[45] W. Sames, F. List, S. Pannala, R. Dehoff, "Metallurgy and processing science of metal additive manufacturing”, International Materials Reviews, vol. 61, n. 5, pp. 315-360, 2016.

[46] I. Maskery, N. Aboulkhair, M. Corfield, C. Tuck, A. Clare, R. Leach, R. Wildman, I. Ashcroft, R. Hague, "Quantification and characterisation of porosity in selectively laser melted Al-Si10-Mg using X-ray computed tomography", Materials Characterization, vol. 111, p. 193-204, 2016.

[47] W. E. Frazler, “Metal Additive Manufacturing: A Review”, JMEPEG, vol. 23, pp. 1917-1928, 2014.

[48] G. Ng, A. Jarfors, G. Bi, H. Zheng, "Porosity formation and gas bubble retention in laser metal", Applied Physics A: Materials Science and Processing, vol. 97, n. 3, pp. 641-649, 2009.

[49] B. Zhang, Y. Li, Q. Bai, "Defect Formation Mechanisms in Selective Laser Melting: A Review", Chinese Journal of Mechanical Engineering (English Edition), vol. 30, n. 3, pp. 515-527, 2017.

[50] ASTM, "ASTM E23. Standard test methods for notched bar impact testing of metallic materials».

[51] N. Pratten, "The precise measurement of the density of small samples", Journal of Materials Science, vol. 16, pp. 1737-1747, 1981.

[52] ASTM, "ASTM E407. Standard practice for microetching metals and alloys».

[53] L. Alves, Foundations of measurement Fractal Theory for the Fracture Mechanism, Applied Fracture Mechanics, 2012.

[54] S. Stach, J. Cybo, J. Chmiela, "Fracture surface - fractal or multifractal?", Materials Characterization, vol. 46, pp. 163-167, 2001.

[55] S. Stach, S. Roskosz, J. Cybo, J. Cwajna, "Multifractal description on fracture morphology: investigation of the fractures of sintered carbides", Materials Characterization, vol. 51, pp. 87-89, 2003.

[56] E. Charkaluk, M. Bigerelle, A. Iost, "Fractals and fracture", Engineering Fracture Mechanics, vol. 61, pp. 119-139, 1998. 
[57] C. Weingarten, D. Buchbinder, N. Pirch, W. Meiners, K. Wissenbach, R. Poprawe, "Formation and reduction of hydrogen porosity during selective laser melting of AlSi10Mg", Journal of Materials Processing Technology, vol. 221, pp. 112-120, 2015.

[58] M. Cabrini, S. Lorenzi, T. Pastore, S. Pellegrini, D. Manfredi, P. Fino, S. Biamino, C. Badini, "Evaluation of corrosion resistance of $\mathrm{Al}-10 \mathrm{Si}-\mathrm{Mg}$ alloy obtained by means of Direct Metal Laser Sintering”, Journal of Materials Processing Technology, vol. 231, pp. 326-335, 2016.

[59] L. Girelli, M. Tocci, M. Gelfi, A. Pola, "Study of heat treatment parameters for additively manufactured AlSi10Mg in comparison with corresponding cast alloy", Materials Science \& Engineering A, vol. 739, pp. 317-328, 2018.

[60] X. Liu, Z. Liu, Y. Jiang, G. Wang, Y. Yang, L. Zhang, "Gradient in microstructure and mechanical property of selective laser melted AlSi10Mg", Journal of Alloys and Compounds, vol. 735, pp. 1414-1421, 2018.

[61] D. Dai, D. Gu, H. Zhang, J. Xiong, C. Ma, C. Hong, R. Poprawe, "Microstructure and tensile properties of selective laser melting additive manufactured aluminum based parts", Optic and Laser Technology, vol. 99, pp. 91-100, 2018.

[62] W. Li, S. Li, J. Liu, A. Zhang, Y. Zhou, Q. Wei, C. Yan, Y. Shi, "Effect of heat treatment on AlSi10Mg alloy fabricated by selective laser melting: microstructure, evolution, mechanical properties and fracture mechanism”, Materials Science and Engineering A, vol. 663, pp. 116-125, 2016.

[63] X. Li, W. Wang, M. Saunders, A. Suvorova, L. Zhang, Y. Liu, M. Fang, Z. Huang, T. Sercombe, “A selective laser melting and solution heat treatment refined Al-12Si alloy with a controllable ultrafine eutectic microstructure and 25\% tensile ductility”, Acta Materialia, vol. 95, pp. 74-82, 2015. 